\title{
Airborne spread of expiratory droplet nuclei between the occupants of indoor environments: a review
}

\section{Ai, Z.T.; Melikov, Arsen Krikor}

Published in:

Indoor Air

Link to article, DOI:

10.1111/ina.12465

Publication date:

2018

Document Version

Peer reviewed version

Link back to DTU Orbit

Citation (APA):

Ai, Z. T., \& Melikov, A. K. (2018). Airborne spread of expiratory droplet nuclei between the occupants of indoor environments: a review. Indoor Air, 28(4), 500-524. https://doi.org/10.1111/ina.12465

\section{General rights}

Copyright and moral rights for the publications made accessible in the public portal are retained by the authors and/or other copyright owners and it is a condition of accessing publications that users recognise and abide by the legal requirements associated with these rights.

- Users may download and print one copy of any publication from the public portal for the purpose of private study or research.

- You may not further distribute the material or use it for any profit-making activity or commercial gain

- You may freely distribute the URL identifying the publication in the public portal

If you believe that this document breaches copyright please contact us providing details, and we will remove access to the work immediately and investigate your claim. 
DR. ZHENGTAO AI (Orcid ID : 0000-0003-2635-2170)

Article type : Review Article

\title{
Airborne spread of expiratory droplet nuclei between the occupants of indoor environments: a review
}

\author{
Z.T. Ai*, A.K. Melikov \\ International Centre for Indoor Environment and Energy, Department of Civil Engineering, \\ Technical University of Denmark
}

*Corresponding email: zheai@byg.dtu.dk

\section{ORCID:}

Z.T. Ai: 0000-0003-2635-2170

A.K. Melikov: 0000-0003-0200-6046

\begin{abstract}
This paper reviews past studies of airborne transmission between occupants in indoor environments, focusing on the spread of expiratory droplet nuclei from mouth/nose to mouth/nose for non-specific diseases. Special attention is paid to summarizing what is known about the influential factors, the inappropriate simplifications of the thermofluid boundary conditions of thermal manikins, the challenges facing the available experimental techniques, and the limitations of available evaluation methods. Secondary issues are highlighted and This article has been accepted for publication and undergone full peer review but has not been through the copyediting, typesetting, pagination and proofreading process, which may lead to differences between this version and the Version of Record. Please cite this article as doi: 10.1111/ina.12465

This article is protected by copyright. All rights reserved.
\end{abstract}


some new ways to improve our understanding of airborne transmission indoors are provided. The characteristics of airborne spread of expiratory droplet nuclei between occupants, which are influenced correlatively by both environmental and personal factors, were widely revealed under steady-state conditions. Owing to the different boundary conditions used, some inconsistent findings on specific influential factors have been published. The available instrumentation was too slow to provide accurate concentration profiles for time-dependent evaluations of events with obvious time characteristics, while CFD studies were mainly performed in the framework of inherently steady Reynolds-averaged Navier-Stokes modelling. Future research needs in three areas are identified: the importance of the direction of indoor airflow patterns, the dynamics of airborne transmission, and the application of CFD simulations.

Keywords: Airborne transmission; cross-infection risk; experiment; CFD; manikin; review

\section{Practical implications}

This literature review makes it possible to draw two main conclusions. First, the influence of various parameters is not straightforward. This must be taken into account when formulating control measures for the transmission of airborne infectious diseases indoors. Second, fast, transient, measurements and/or simulations are required to adequately describe the dynamics of airborne transmission for events with obvious time characteristics.

This article is protected by copyright. All rights reserved. 


\section{Introduction}

Airborne transmission has been shown to be a valid person-to-person respiratory transmission route for a number of infectious diseases. ${ }^{1-2}$ It has become an important research topic within the indoor air sciences. ${ }^{3-9}$ Although airborne transmission has been shown to occur over larger distances, such as between different rooms on a same floor ${ }^{10-11}$, between different flats in the same building ${ }^{12-18}$, and even between adjacent buildings ${ }^{11}$, this paper focuses only on that within an enclosed indoor space.

Airborne transmission between occupants indoors takes place mainly by the generation of infectious droplets from an infected person, the spread of infectious droplet nuclei indoors, and the inhalation of infectious droplet nuclei by an exposed person, ${ }^{19-21}$ as illustrated in Figure 1. Human respiration activities, such as breathing, talking, coughing and sneezing, can generate tens of thousands of droplets. ${ }^{6,22-26}$ The majority of these droplets evaporate fast to half of their initial size and become droplet nuclei. ${ }^{20}$ In particular, the evaporation process completes instantaneously for small droplets with an initial size of less than $20 \mu \mathrm{m} .{ }^{20}$ Some previous studies show that droplets from human respiration activities are mostly less than 5$10 \mu \mathrm{m}$ in diameter. ${ }^{22,27-34}$ This size range is considered to be the lower cut-off size for droplets and is used to differentiate between airborne and droplet transmission (the latter occurs over short distances by direct transfer between occupants of relatively large respiratory droplets). Owing to various influential factors, including particularly the air humidity ${ }^{35}$, different cut-off sizes were suggested in different contexts. ${ }^{3,36-37}$ Lindsley et al. ${ }^{38}$ measured influenza virus in droplet nuclei generated by a coughing patient and reported that $42 \%$ of detected viruses were found in droplet nuclei $<1 \mu \mathrm{m}, 23 \%$ in droplet nuclei of 1-4 $\mu \mathrm{m}$ and $35 \%$ in droplet nuclei $>4 \mu \mathrm{m}$. Airborne droplet nuclei could remain suspended in air for a prolonged period and be transported over an extended distance by indoor airflows. ${ }^{9,23,39-}$ 
${ }^{42}$ Considering also the long survival time of many pathogens in aerosols ${ }^{6,43-44}$ and the increased ability of small particles to penetrate into the lower respiratory tract, ${ }^{6,36,45-46}$ airborne transmission via virus-laden droplet nuclei may constitute a high risk of crossinfection.

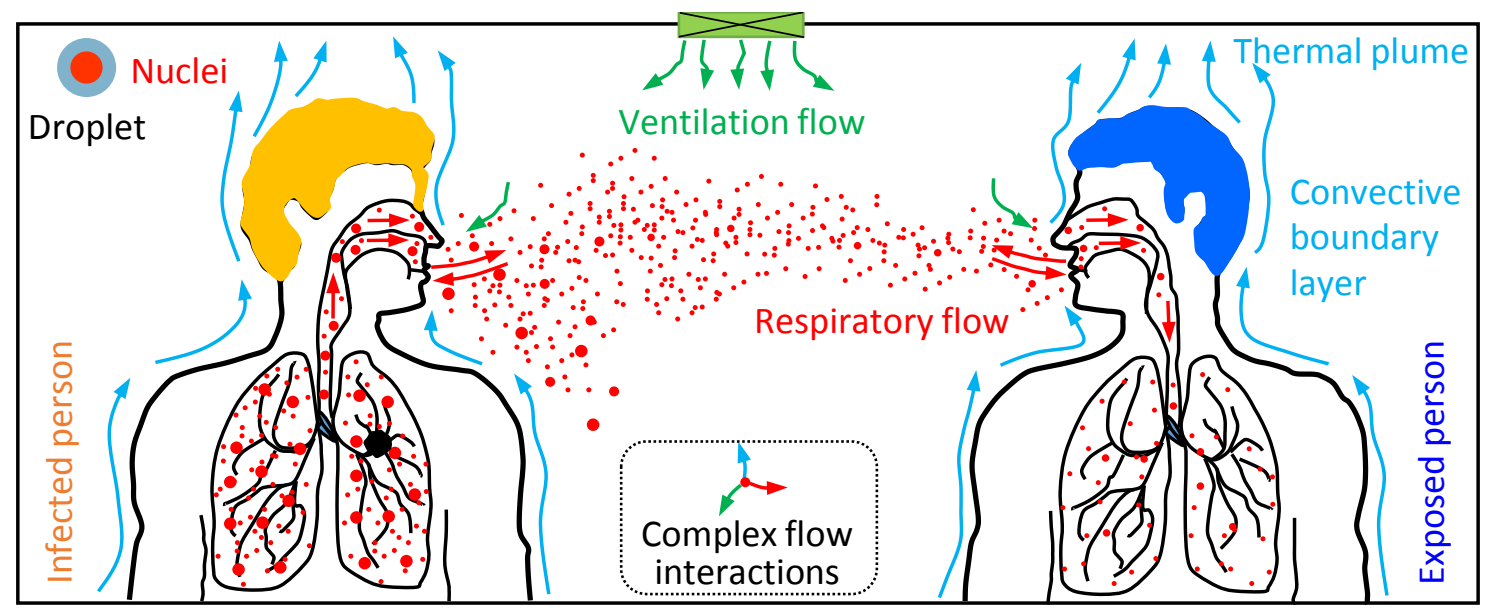

Figure 1 A schematic view of the whole process of airborne transmission indoors and the general governing flows of droplet nuclei dispersion.

The spread of droplet nuclei between occupants of the same indoor space is strongly influenced by the complex interaction ${ }^{47-48}$ of ventilation flow, human body boundary layer flow, ${ }^{47}$ and respiratory flow (see Figure 1). Ventilation is widely recognized as the most influential engineering method for controlling airborne transmission indoors. ${ }^{41,49-55}$ Room air pattern and ventilation airflow rate are two key factors shaping indoor air distribution. Compared to the total volume air distribution, advanced air distribution methods, such as Personalized Ventilation $(\mathrm{PV})^{56}$ and Personalized Exhaust $(\mathrm{PE})^{57}$, have shown a better performance in reducing the risk of cross-infection by airborne transmission. ${ }^{58}$ Recent studies $^{47,59-60}$ of the human micro-environment reveal that the rising plume around a human body could, on the one hand, entrain pollutants in the vicinity and elevate the exposure concentration, ${ }^{61-62}$ and on the other hand, function as an air curtain that protects the occupant 
from the incursion of expiratory flows from others. ${ }^{47}$ The characteristics of breathing flows depend strongly on breathing activities ${ }^{63-64}$ and breathing modes ${ }^{47,65-66}$. Obviously, coughing and sneezing generate a higher expiratory speed and droplet concentration but a lower event duration and frequency when compared to breathing and talking. While inhalation from both mouth and nose is aerodynamically the same,${ }^{66}$ exhalation from mouth and nose produce very different expiratory flow patterns. ${ }^{48,63-64,67}$ In addition, some important parameters, such as the relative distance between the infected and exposed occupants, their posture and relative orientation, and occupant movements in the vicinity, all further complicate the interaction of airflows and thus increase the uncertainty of airborne transmission. Although many consistent findings regarding these parameters have been obtained from past studies, some inconsistent aspects and even unexplored areas still await investigation.

In engineering field, airborne transmission between occupants indoors is usually investigated using both experimental and CFD methods. Experimental methods include physical measurement of the concentration field in breathing zones and imaging visualization of expiratory flows. ${ }^{67-76}$ Chamber experiments using breathing thermal manikins ${ }^{65-66}$ have been the primary method of investigating airborne transmission between occupants and to quantify the risk of cross-infection. ${ }^{66}$ Breathing, coughing, and sneezing can be simulated using ancillary machines ${ }^{77-78}$, while droplet nuclei formed by the human respiratory processes are usually simulated using a tracer gas and particles. In general, chamber experiments can provide reliable results as they take full account of the indoor aerodynamics of real ventilation flows and tracer gas/particles. However, they are low-resolution in both space and time. As an alternative, CFD methods ${ }^{79}$ employing computational thermal manikins and wellestablished mathematical models for the transport of tracer gas/particles can provide a highresolution whole-field flow and concentration data. ${ }^{48,80-83}$ However, CFD simulations must be 
experimentally validated and they are very dependent on the knowledge of the practitioners. In addition, past CFD simulations of airborne transmission indoors employed mostly Reynolds-averaged Navier-Stokes (RANS) two-equation turbulence models, ${ }^{84-85}$ which have inherent deficiencies in capturing complex and dynamic flow interactions. For both experimental and CFD studies, a basic prerequisite is the proper definition of thermofluid boundary conditions of thermal manikins, which are compromised by our limited knowledge of the thermofluid boundary conditions of human beings.

A good understanding of airborne transmission is fundamental for formulating effective control measures for an outbreak of infectious disease. The objective of this paper is to provide a review of past studies of airborne transmission between occupants indoors. Neither microbiological and medical studies on the mechanisms of droplet generation from mucus to mouth/nose and the deposition from mouth/nose onto mucus, nor the viability and infectivity of infectious agents have been included. Four closely associated topics of airborne transmission indoors are covered in the following sections: the influential factors, the thermofluid boundary conditions of thermal manikins, the research techniques and the evaluation methods. The review was conducted as a systematic investigation of relevant publications in peer-reviewed journals and proceedings, and of professional standards issued by leading international organizations. Particular attention was paid to studies that complied with the following criteria: well-justified research methodology, quantitatively evaluated cross-infection risk, and accurately simulated human body geometry. The limitations of published studies falling within the above four topics are discussed, inconsistent findings and some underinvestigated areas are identified, and future perspectives for improved understanding of airborne transmission indoors are discussed. 


\section{Current understanding of airborne transmission indoors}

This section is intended to review the general influence of factors on the airborne transmission indoors. However, it should be noted that different types of indoor environment (e.g., residential buildings, office buildings, schools, hospitals and aircraft cabins) could have very distinctive issues and characteristics of airborne transmission, basically because of their different geometries and layouts of indoor spaces, air distribution methods, supply flow rates, occupant densities, occupants' behaviours, etc. ${ }^{86}$ For examples, residential buildings do not have a fixed layout of occupants and they are mostly naturally ventilated when the outdoor air temperature is acceptable. Office buildings are typically ventilated by mechanical ventilation systems, where the layouts of occupants are usually fixed. Schools, mostly classrooms, have high occupant densities and specific building and ventilation designs, as well as strongly dynamic movements. Hospitals, mostly hospital wards and consultation rooms, normally have high $\mathrm{ACH}$ values and specific layouts and postures of occupants. Aircraft cabins and other vehicle indoor environments have very high occupant densities, special ventilation designs and occupants' layout.

\subsection{The importance of air distribution}

Commonly used total volume air distribution methods include mixing ventilation (MV), displacement ventilation (DV), under floor air distribution (UFAD), and downward ventilation $(\mathrm{DnV}) .{ }^{87-88}$ In addition, more and more studies show the benefits of combining these basic air distribution methods with advanced ventilation technologies, such as PV and PE. 


\subsubsection{Total volume air distribution}

Past studies that have evaluated the influence of MV, DV and UFAD on airborne transmission reported some inconsistent findings. Some studies ${ }^{58,81,89-90}$ suggested that DV and UFAD are better at reducing the risk of cross-infection than MV, whereas other studies ${ }^{90-}$ ${ }^{93}$ show that MV performs better than DV and UFAD. Studies finding that DV and UFAD perform better than MV demonstrated that the vertical diluting function of DV and UFAD can reduce the horizontal dispersion of exhaled flows and can thus reduce the risk of crossinfection. This finding was found to be valid not only for tracer gas ${ }^{81,89-90}$ but also for small particles less than $5 \mu \mathrm{m}$ in diameter. ${ }^{81,90}$

The studies reporting that MV performs better than DV and UFAD were usually based on two findings. First, that droplet nuclei could travel a longer distance indoors with DV than with MV..$^{90,92-94}$ Second, that expiratory droplet nuclei could be more easily trapped in the breathing zone by the thermal stratification created by DV and UFAD..$^{91-92,95}$ Both findings imply that a lower exposure risk for co-occupants can be achieved with MV. The different findings may be attributed to the different airflow interactions in the two types of air distribution and to the boundary conditions used in the different studies. It should be highlighted that the influence of boundary conditions could be comparable to that of the air distribution methods. In addition, the relative importance of the two functions of DV, namely diluting pollutants vertically and increasing pollutants dispersion horizontally, may change with distance ${ }^{81,90}$ and vertical location of the exhaust opening ${ }^{96}$. It is therefore important to clarify the exact boundary conditions when interpreting a specific finding.

This article is protected by copyright. All rights reserved. 
$\mathrm{DnV}$ is recommended for hospital environments. ${ }^{97-99}$ However, the downward flow often cannot penetrate the microenvironment around supine patients, leading to a high risk of crossinfection. ${ }^{100}$ The underperformance of $\mathrm{DnV}$ is basically due to the counteraction of the buoyancy-driven thermal plumes generated from occupant(s) and heat sources against the momentum-driven downward flows from supply diffuser(s). ${ }^{101-102}$ The interaction between the upward and downward flows is governed by the dimensions of ceiling diffuser(s), the location of occupant(s) and other heat sources, the momentum of the supply flows, and the intensity of the buoyancy generated from occupant(s) and other heat sources. In addition, it was reported that the location of the return openings can be optimized to better distribute the infectious expiratory flows. ${ }^{52}$

\subsubsection{Advanced air distribution}

The excellent performance of PV in reducing the risk of airborne infection in indoor spaces conditioned by various background ventilation methods has been widely documented in the literature ${ }^{58,103-105}$ which suggests that PV can be a suitable supplement to traditional methods of infection control. The efficiency of PV in mitigating airborne transmission is influenced by the type of PV and the air terminal devices used. ${ }^{58,81,106}$ Pantelic et al. ${ }^{69}$ reported that, compared to MV, desk-based PV could reduce the intake of cough-released droplets by $41-99 \%$. This efficiency is higher when the distance between the exposed individual and the cough generator is small. ${ }^{68}$ However, their studies were limited to situations in which the PV is used only by the exposed individual, not the infected source.

This article is protected by copyright. All rights reserved. 

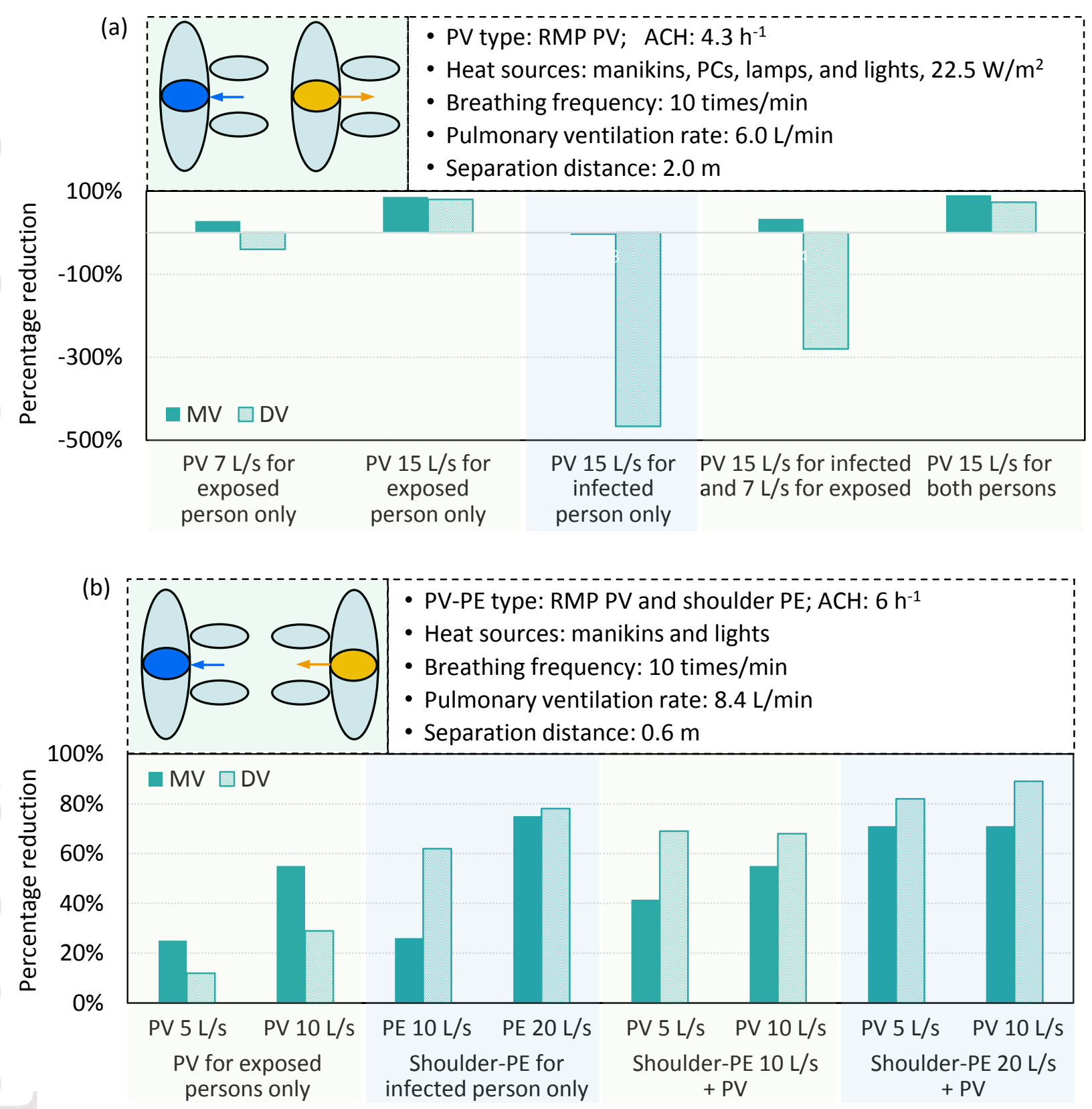

Figure 2 Percentage reduction (compared to the case with no PV) in the intake of the expiratory flow from the infected individual (yellow) by the exposed individual (blue) when using $\mathrm{PV}^{58}$ (a) and using PV and/or $\mathrm{PE}^{107}$ (b), where RMP denotes a round movable panel mounted on a movable arm-duct attached to a desktop.

Obviously, the use of PV by the infected individual would increase the dispersion of exhaled pollutants, and the resultant risk of cross-infection would then depend on the direction of supplied PV airflow, the background air distribution pattern and the orientation 
of the infected and exposed individuals. Li et al. ${ }^{81}$ investigated the risk of cross-infection between two face-to-face individuals with a separation distance of $2 \mathrm{~m}$, where the PV supplied airflow upwards. They found that when only the infected individual uses PV, the risk of cross-infection is lower than that when DV is used alone but is slightly higher than when MV is used alone. Cermak and colleagues ${ }^{58,104}$ examined a face-to-back arrangement with the infected individual in front, where the PV supplied airflow horizontally towards the person. It was reported that the use of PV by the infected individual could result in a significant increase in the risk of cross-infection with DV, even when the exposed individual also uses PV (see Figure 2 (a)). In general, these findings imply that the use of PV by an infected individual should be avoided.

Various types of PE devices have been investigated in different situations, including topPE and shoulder-PE for a patient in a consultation room, ${ }^{89}$ wearable PE for an infected doctor, ${ }^{57}$ a bed integrated local exhaust system for a supine patient ${ }^{108-109}$ and seat-mounted local exhaust in an aircraft cabin. ${ }^{111}$ In general, all types of PE showed excellent performance in controlling the source of airborne transmission, although their efficiency was influenced by other factors, including their relative orientation to the infected individual. The use of PE for an infected individual shows much better performance when compared to the use of PV for a healthy individual only (Figure 2 (b)). It is important to realise that the use of PV helps a little when PE is already used, although the combination of PV-PE can achieves the lowest crossinfection risk. ${ }^{107}$ Such a PV-PE combination is also effective in capturing the expiratory flow and thus reducing the risk of cross-infection in aircraft cabins. ${ }^{111}$ For PV and PE and their combination, a systematic investigation of the influential factors and their increased flexibility in various situations, such as different background ventilation methods and relative 
orientation of occupants, is necessary to improve their performance in controlling airborne transmission.

\subsection{The importance of supply flow rate}

A minimum air change rate per hour $(\mathrm{ACH})$ is usually recommended by ventilation standards and guidelines ${ }^{112-113}$ to maintain an acceptable IAQ or to control personal exposure, which is based on the complete-mixing theory that a certain amount of fresh air can dilute the concentration of airborne pollutants. This recommendation was supported by several studies. ${ }^{51,52,92}$ However, Grosskopf ${ }^{53}$ stated that increasing $\mathrm{ACH}$ is not necessarily an effective method if the pollutant is released continuously at a certain location and the concentration is non-uniform in the space. Bolashikov and colleagues ${ }^{54,108,114-115}$ conducted a series of experiments to examine the influence of $\mathrm{ACH}$ on cross-infection in a hospital environment. They reported that, under certain circumstances, a higher exposure of coughed $\mathrm{CO}_{2}$ can be measured at $12 \mathrm{~h}^{-1}$ rather than at $6 \mathrm{~h}^{-1}$ and $3 \mathrm{~h}^{-1}$. It was concluded that the complex flow interaction around a human body does not interact linearly with a change of ACH. A study by Pantelic and Tham ${ }^{55}$ proved again that increasing ACH could increase exposure risk. They suggested that $\mathrm{ACH}$ should not be used as the sole indicator of the performance of ventilation systems in reducing exposure to airborne agents. Figure 3 provides a summary of the evidence showing that increasing the $\mathrm{ACH}$ could contribute to an increased exposure. In general, increasing the $\mathrm{ACH}$ would have two possible effects to the spread of expiratory droplet nuclei: enhancing the dilution and increasing the dispersion. The former would decrease the risk of cross-infection but the latter could increase the risk, given that the expiratory flow has an obvious direction. Such a counteraction between the two effects should become more significant in the period before the steady-state condition is achieved. Further studies are still required to clarify this counteracting effect under both 
steady-state and transient conditions. Despite of the fact that the risk of cross-infection could increase with the increase of $\mathrm{ACH}$ under some arrangements, it must be borne in mind that the design practices normally assume the complete-mixing conditions. .
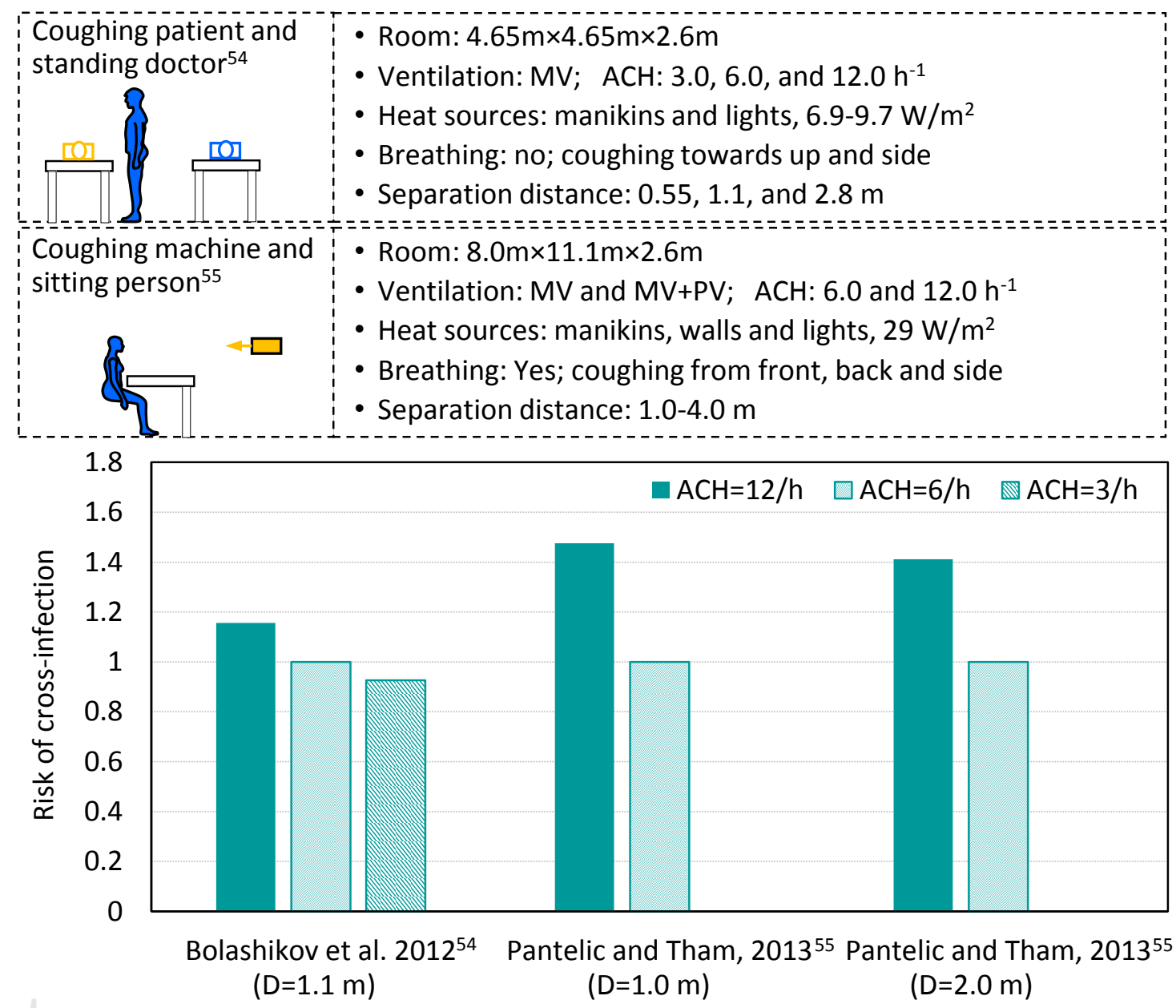

Figure 3 Risk of cross-infection due to coughed flows in front under different ACH values; the risks were normalized by those at $\mathrm{ACH}=6 \mathrm{~h}^{-1}$; for the study by Bolashikov et al ${ }^{54}$, the exposed peak concentration was used as an indicator for the risk, and for the study by Pantelic and Tham ${ }^{55}$, the volume of droplets in the breathing zone was used as an indicator for the risk; D denotes separation distance between the source and the exposed manikin..

\subsection{The importance of relative distance}

A qualitative relationship between the risk of cross-infection and relative distance from infected occupant is shown in Figure 4. In general, the risk of cross-infection will be high when the infected and the exposed individuals are positioned so closely that breathing flows 
can approach each other's faces. The risk decreases sharply with the increase of distance down to a certain threshold distance, at which the exposure corresponds approximately to what it would be with complete mixing. A knowledge of this threshold distance is important for selecting the correct measures for controlling airborne transmission. The fact is that different studies have suggested different threshold distances, including $0.8 \mathrm{~m}$ between two standing individuals ${ }^{100,116}$ and between two supine individuals, ${ }^{52} 1.0 \mathrm{~m}$ between two standing or one standing and one sitting individuals, ${ }^{117} 1.1 \mathrm{~m}$ between a supine and a standing individual, ${ }^{54,118}$ and 1.0-1.5 m between two standing individuals. ${ }^{119}$ The difference of the reported threshold distances is probably due to the different influential factors and thus different boundary conditions that were considered in the studies.

Villafruela et al. $^{48}$ investigated the role of various flows in determining airborne transmission between two individuals at different distances. They reported that the human microenvironment and the interaction between breathing flows are the key factors determining the airborne transmission over short distances $(<0.5 \mathrm{~m})$, while the indoor ventilation flow is more important for long distances $(>0.5 \mathrm{~m})$. After evaluating this effect under five different air distribution systems, Nielsen et al. ${ }^{120}$ explained that the level of crossinfection is contributed from two routes: one is through the mixed room air as background concentration and the other is through the direct exhaled flow from the infected individual. Such a finding leads to two observations. First, since the use of PV and PE can modify the human microenvironment and thus the flow interactions around the breathing zone, it should change our current understanding of the relationship between relative distance and the risk of cross-infection. ${ }^{68-69}$ Second, the indoor ventilation flow is important because it determines the threshold distance defined above. However, the characteristics of indoor ventilation flow, 
especially its direction, have rarely been taken into account in past studies. These topics should be the focus of future studies.

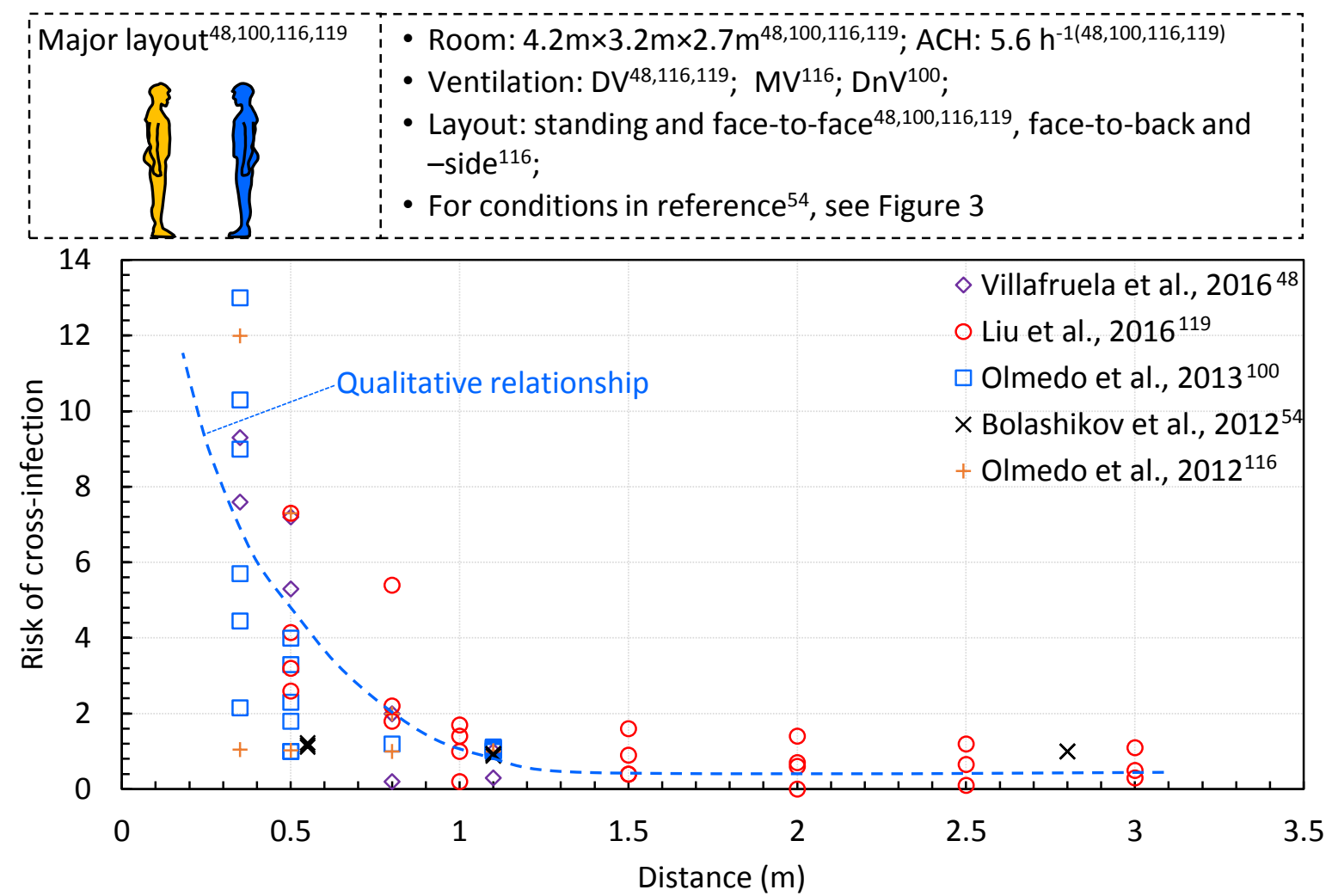

Figure 4 A summary of the general relationship between the risk of cross-infection and distance from the infected source; the variation of the quantitative relationship is influenced by many factors, including ventilation method, ${ }^{116}$ relative location to the supply diffuser and exhaust grille, ${ }^{100}$ relative orientation, ${ }^{116} \mathrm{ACH},{ }^{54}$ and breathing mode ${ }^{119}$ the distance ranges investigated and the different normalization methods.

(a) Face-to-face

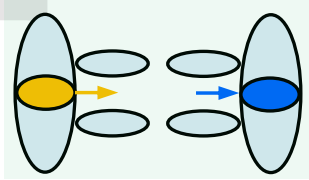

(b) Face-to-face at $45^{\circ}$

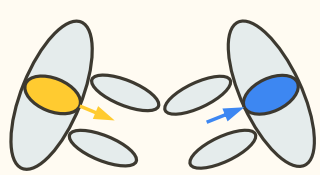

(f) Sitting and standing
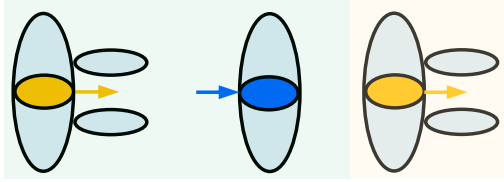

(c) Sitting and standing (d) Face-to-side
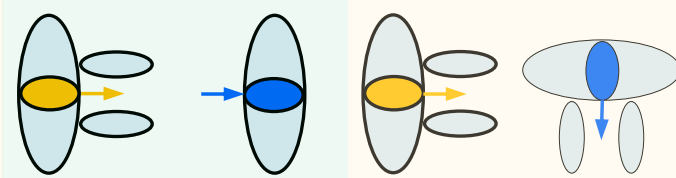

(e) Face-to-back

(h) Face-to-face at $45^{\circ}$

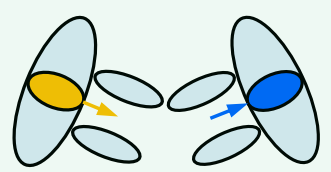

Figure 5 Influence of relative orientation and posture on cross-infection risk, where the cross-infection risk decreases from (a) to (e) when using $\mathrm{MV}^{69,107,116}$ and from (f) to (h) when using $\mathrm{DV}^{107}$; note that the left-hand manikin represents the infected individual and the righthand one the exposed individual.

This article is protected by copyright. All rights reserved. 


\subsection{The importance of posture and relative orientation}

Owing to the directionality of expiratory flows, posture and relative orientation of infected and exposed individuals are important factors in determining the cross-infection risk, especially over short distances. This is summarized in Figure 5. Using MV, face-to-face orientation causes the highest risk of cross-infection and face-to-back the lowest risk. ${ }^{69}$ Using DV, one sitting and one standing occupant causes the highest risk, ${ }^{107}$ as the upward flow generated by DV increases the transmission of expiratory flows from a sitting individual to a standing individual. ${ }^{116}$

For hospital wards, the maximum exposure of a standing doctor and a second patient is found when the patient is lying sideways and facing them, and the minimum exposure is observed when the patient is lying on his back ${ }^{54}$ or sitting up ${ }^{52}$. A doctor standing sideways can reduce the exposure considerably. In general, the high risk of cross-infection between two closely located, face-to-face, occupants is caused by the mutual penetration of their breathing flows. In this connection, the head posture of both individuals would have a considerable influence on the possibility and degree of interaction of the two breathing flows, although this has rarely been investigated.

The human head is not limited to facing straight forward or to a fixed position. It is quite usual to rotate the head from time to time, to face horizontally from right to left and vertically from ground to ceiling. The posture of the head directly determines the exhalation flow direction, which is one of key factors influencing the risk of cross-infection. Together with various breathing modes, different head postures and their variation in time will cause large variations in the risk of cross-infection between two closely located individuals. Despite of these variations, the worst cases should be paid a special attention.

This article is protected by copyright. All rights reserved. 


\subsection{The importance of breathing function and mode}

The breathing function of the exposed individual is also important for cross-infection evaluation, ${ }^{66}$ as it could result in an approximately $15-30 \%$ change in exposure to approaching airborne pollutants. ${ }^{61}$ A study by Poon and Lai $^{78}$ indicated that it is the exhalation, rather than the inhalation, of the exposed individual that makes the greatest difference. For episodic emissions, the effect of exhalation in reducing inhaled quantity easily overwhelms the enhanced effect of inhalation. Compared to the non-breathing mode, the exhalation cycle reduces the inhaled quantity and this effect increases with breathing rate. However, their study was limited to sneezing activity, which has a high expiratory speed and a short event duration. Moreover, no comparison of the exposure level was made between exhalation through mouth and nose.

\section{$\begin{array}{ll}\text { (a) Breathing mode NM } & \text { (b) Breathing mode MN }\end{array}$}
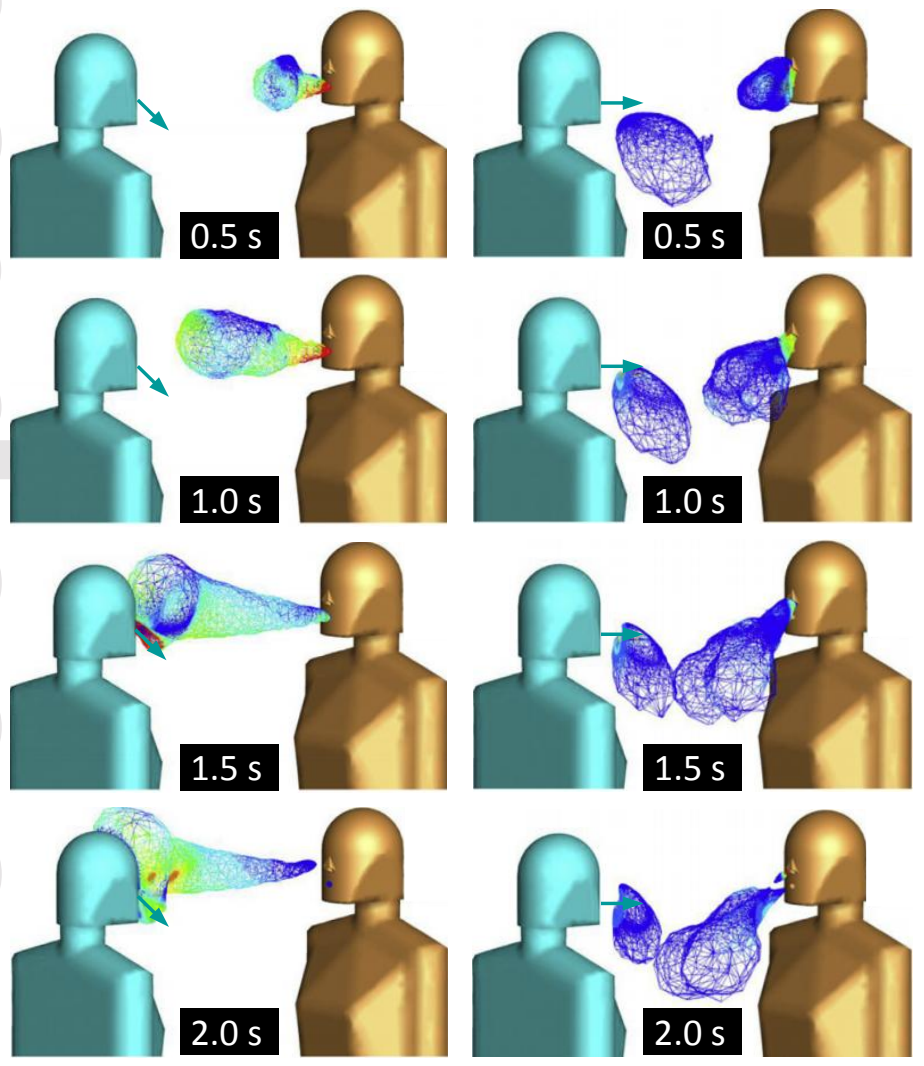

This article is protected by copyright. All rights reserved. 
Figure 6 Iso-surfaces of tracer gas $\mathrm{N}_{2} \mathrm{O}$ concentration equal to $5 \%$ of the concentration in the exhalation of the infected (source) manikin (bronze coloured) at different times, when the relative distance is $0.5 \mathrm{~m}$ and the ventilation method is $\mathrm{DV} ;{ }^{48}$ note that no break between exhalation and inhalation was considered; NM indicates the exhalation modes for the exposed and the infected manikins are through nose and mouth, respectively, while both manikins inhale through the nose; $\mathrm{MN}$ is in reverse for the exhalation modes.

With regard to breathing mode, the exhaled flow through mouth is important for both infected and exposed individuals. ${ }^{48}$ Exhaled flow through the mouth of an infected individual can easily penetrate the breathing region of a nearby individual, while exhaled flow through the mouth of an exposed individual has a cleaning effect on the breathing region. The highest exposure is therefore found when the infected individual exhales from the mouth and the exposed individual exhales from the nose, while the lowest exposure is found when the infected individual exhales from the nose and the exposed individual exhales from the mouth (see Figure 6 for a comparison of these two scenarios). However, the exposure is also dependent on the interaction between the exhaled flow and the strength of the Convective Boundary Layer (CBL), which is functional of several factors (e.g., surrounding air temperature, furniture design and location, clothing, body posture, etc.). In addition, the break between exhalation and inhalation was not considered in these studies. ${ }^{48}$ In fact, the break has a considerable influence on exposure, as an approximately $1.0 \mathrm{~s}$ break period allows the CBL to recover and thus to affect the exposure. ${ }^{122}$ In addition, exhalation through the mouth of an infected individual may cause an even higher exposure risk from airborne transmission than coughing for a nearby exposed individual, ${ }^{119}$ provided that the two are close to each other $(<$ $1.0 \mathrm{~m}$ ). The lower infectious risk due to coughing is because the exposure time of the coughing flow is short, because coughing is highly directional and because it is unusual to face other people when coughing. These findings, especially the directionality and cleaning effect of the exhaled flows, suggest the importance of properly simulating the breathing mode 
when investigating airborne transmission. Measurements made with unrealistic breathing modes, especially non-breathing and only continuous inhalation or exhalation, would cause misleading dosing and sampling at the infected and exposed individuals.

\subsection{The importance of particle size}

A few studies considered different particle sizes when evaluating the risk of crossinfection. Li et al. ${ }^{81,90}$ simulated airborne transmission between occupants using both tracer gas $\left(\mathrm{CO}_{2}\right)$ and particles $(1,5$, and $10 \mu \mathrm{m})$. For normal breathing, using MV and UFAD, the intake fraction (see section 5.1 for definition) decreases with particle size (see Figure 7). This sequence was reversed using DV. A number of other studies ${ }^{61,78,80,82,119}$ examined different particle sizes, but they mostly had no conclusion on the influence of particle size on the risk of cross-infection. Liu and Novoselac ${ }^{123}$ analysed the spread behaviour of three particle sizes $(0.77,2.5$ and $7.0 \mu \mathrm{m})$ generated from a cough and reported that the larger particles have a lower concentration in the vicinity of the receiver occupant in front. However, they used only very simplified dummies at a fixed separation distance of $1.2 \mathrm{~m}$. Further studies are required. Previous studies have reported that small particles, namely $0.7 \mu \mathrm{m},{ }^{124} 3-5 \mu \mathrm{m},{ }^{125}$ and aerosolized Bacilus Subtilus bacteria ${ }^{126}$ behave very like tracer gas in ventilated indoor environments. Our recent studies ${ }^{127}$ further compared the human exposed concentration of tracer gas and monodispersed particles $(0.07 \mu \mathrm{m}, 0.7 \mu \mathrm{m}$ and $3.5 \mu \mathrm{m})$ using a thermal manikin and the findings confirmed that tracer gas can be used reliably to simulate these small particles in measurements of airborne transmission.

This article is protected by copyright. All rights reserved. 


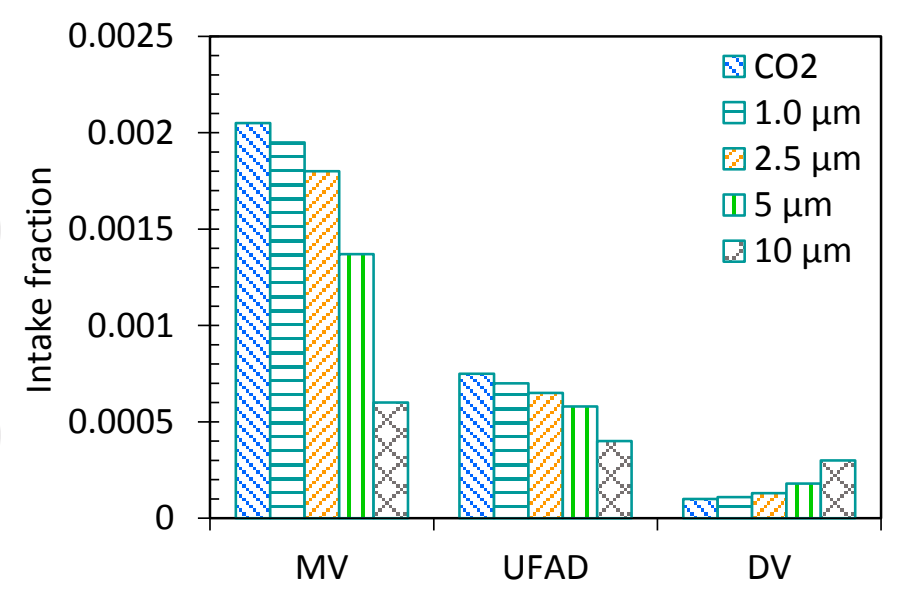

Figure 7 Intake fraction of a co-occupant for the pollutants exhaled by an infected individual $;{ }^{90}$ the same trend was observed when PV was used. ${ }^{81}$

\subsection{The importance of human movement}

Human movements investigated in the past included hand, arm and whole-body movements. It has been reported that the localized hand motions of a sitting person had insignificant effects on the thermal plume above the head of that person ${ }^{61}$, while the arm movement influenced the dispersion of pollutants in the breathing zone and thus should be included in exposure analysis ${ }^{128}$.

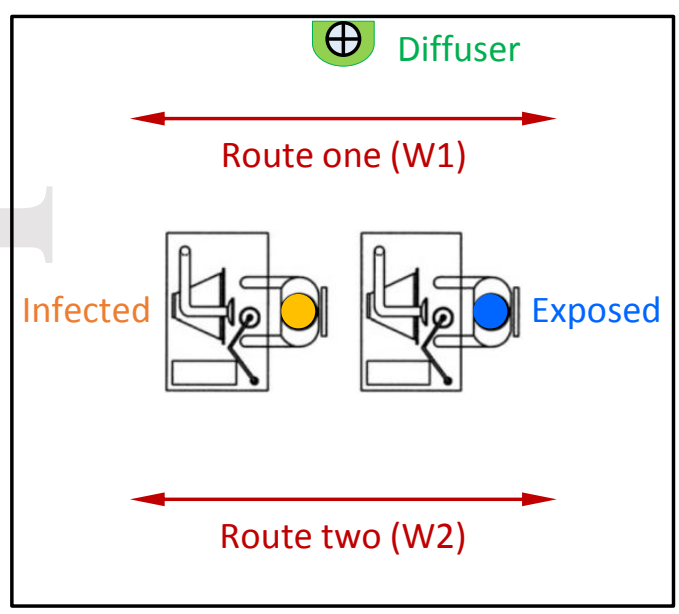

This article is protected by copyright. All rights reserved. 


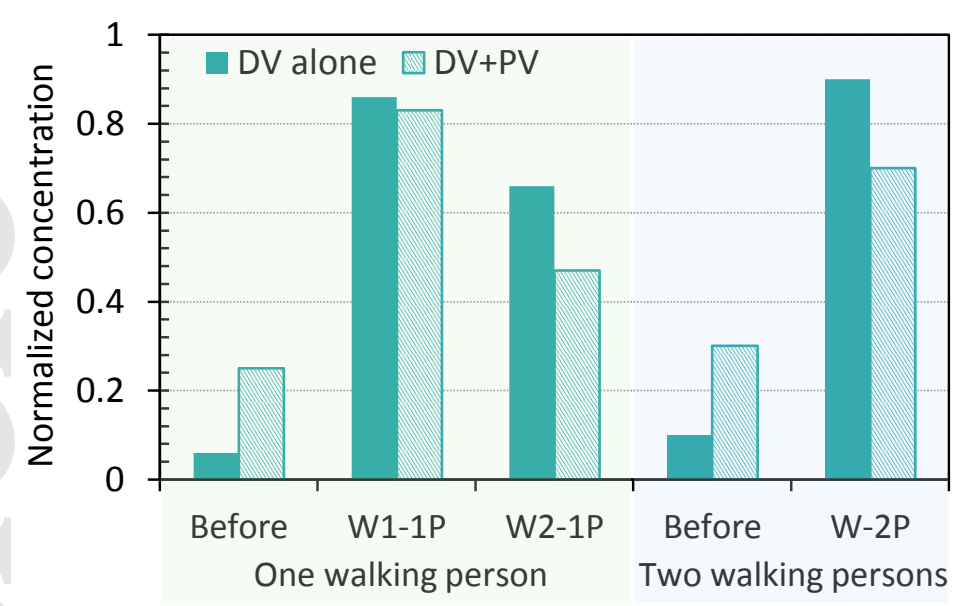

Figure 8 Influence of human movement on the co-occupant's exposed concentration of pollutants exhaled by an infected individual in a room with DV and PV, ${ }^{134}$ where 'before' represents the background condition in which nobody is walking, W1-1P only one person walking on route one (close to a DV diffuser), W2-1P only one person walking on route two (at a distance from a DV diffuser), and W-2P two persons walking, one on each route.

A moving human body can create much stronger air movements than hand and arm motions. Locally, the air movements created by a moving person can overwhelm that person's body thermal plumes when the walking speed is above $0.2 \mathrm{~m} / \mathrm{s}^{129}$ They can also easily break down the stratification of the expiratory flow and the CBL around a nearby person. ${ }^{117}$ In general, a walking person enhances air mixing in the whole room, ${ }^{130}$ which could result in unexpected spread of pollutants. ${ }^{131}$ Some examples of increased risk of crossinfection due to a moving person can be found in past studies. ${ }^{132-134}$ Particularly, a numerical study by Han et al. ${ }^{135}$ shows that in an aircraft cabin, the walking of a crew member may not considerably increase the risk of cross-infection to seated passengers, but the walking person himself/herself does have a higher exposure risk due to the vortexes generated. Certainly, this finding is dependent on the location of the infected person in relation to the walking person. In addition, the influence of walking on airborne transmission between occupants in a room using DV was quantitatively examined ${ }^{134}$ (see Figure 8 ). The increased air mixing caused by walking resulted in a considerable increase in the risk of cross-infection. As might be expected, walking closer to the displacement diffuser caused greater disturbances. The 
presence of a second walking person had only a slight influence on the exposed concentration when compared to the scenario with only one person walking near the diffuser.

Although the considerable influence of human movements on indoor flow and concentration distributions have been shown, the influence of occupant movements on airborne transmission between individuals has been less thoroughly investigated. In addition, moving speed and other related activities such as door opening should be expected to have an influence on airborne transmission ${ }^{136-137}$, and they should be explored in future research.

Apart from the influential factors reviewed above, there are some important factors that were less investigated in the past studies. The design of the chair and the distance between the table and the body play an important role in the formation and characteristics of the CBL around the human body and the thermal plume above the body and thus influence exposure. ${ }^{59,138-139}$ However, the influence of the furniture on the risk of cross-infection between occupants has not been investigated. The metabolism can influence both the breathing characteristics and the CBL around a person ${ }^{140,143}$, which would therefore influence the risk of cross-infection. This applies to both the infected and the exposed individual. In addition, difference in the height of the infected and the exposed individual was shown to be another important factor. ${ }^{140}$

\section{Thermofluid boundary conditions for thermal manikins}

\subsection{Thermal characteristics of bodies}

The thermal characteristics (namely, the heat power, surface temperature and clothing insulation) of a thermal manikin have an important influence on its microenvironment, especially when the local ventilation flow is relatively weak. ${ }^{47,66,102}$ An elevated room air 
temperature results in an increased surface temperature, which in turn decreases the development of the CBL around the thermal manikin. ${ }^{102}$ However, the influence of room air temperature on airborne cross-infection is still awaiting exploration. The heat power of a thermal manikin was usually defined to be a constant value ranging from 60 to $102 \mathrm{~W} .^{61,95,103}$ The surface temperature range between different body segments was specified to be 29-34.5 ${ }^{\circ} \mathrm{C} .{ }^{62,100,116,119}$ Light clothing with an overall thermal insulation ranging from 0.5 clo to 0.8 clo was widely used. ${ }^{69,89,103,111,117}$ The estimation of clothing insulation values usually followed ISO Standard $9920 .{ }^{141}$

These body thermal characteristics defined in past studies are slightly different from the human subject studies reported in the ASHRAE Handbook. ${ }^{142}$ Typically, human skin temperatures during sedentary activities in a state of thermal comfort are $33-34{ }^{\circ} \mathrm{C}$. The sensible heat output for a resting adult is about $58 \mathrm{~W} / \mathrm{m}^{2}$, or $55-70 \mathrm{~W} / \mathrm{m}^{2}$ for sedentary office activities. In a thermally neutral condition, these thermal characteristics depend strongly on physical activity and room air temperature. ${ }^{143}$

Clothing insulation also has an important influence on the development of CBL and thermal plume, which would therefore influence the risk of cross-infection. The study by Licina et al. ${ }^{59}$ suggested that the clothing insulation has an obvious influence on the peak velocity of CBL in the breathing zone of a manikin. Compared to the nude case, the thin and the thick clothing ensembles reduce the peak velocity from $0.205 \mathrm{~m} / \mathrm{s}$ to $0.166 \mathrm{~m} / \mathrm{s}$ and 0.124 $\mathrm{m} / \mathrm{s}$, respectively. Zukowska et al. ${ }^{174}$ reported that, compared to the nude case, the loose clothing changes the shape and increases the volume flux of the plume above the manikin head by $24 \%$, while tight clothing and chair design do not affect the volume flux of the plume.

This article is protected by copyright. All rights reserved. 


\subsection{Geometry of mouth and nose}

The geometry of the mouth and nose influences the characteristics of breathing flows, particularly the speed and direction of expiratory flows. Table 1 summarizes the geometrical characteristics of the mouth and nostrils of manikins as defined in past studies. There were three shapes for the mouth opening, namely semi-ellipsoid, circular and ellipsoid, while nostril openings were all circular. Area of the mouth opening ranged from $100 \mathrm{~mm}^{2}$ to 123 $\mathrm{mm}^{2}$ during normal breathing, but exceeded $300 \mathrm{~mm}^{2}$ during coughing. ${ }^{54,82}$ The total area of the nostrils during normal breathing varied considerably, from 100 to $226 \mathrm{~mm}^{2}$, and was defined as $330 \mathrm{~mm}^{2}$ during coughing. ${ }^{82}$ The limited and varied data was available from human subject tests. Grymer et al. ${ }^{145}$ reported that the mean area of nostrils during normal breathing was $264 \mathrm{~mm}^{2}$. Gupta et al. ${ }^{63}$ reported that the opening area of the mouth during normal breathing was $120 \pm 52 \mathrm{~mm}^{2}$ for male and $116 \pm 67 \mathrm{~mm}^{2}$ for female subjects, while those of the nostrils were $142 \pm 46 \mathrm{~mm}^{2}$ for male and $112 \pm 20 \mathrm{~mm}^{2}$ for female subjects. During coughing, it was found that the mouth opening area was $400 \pm 95 \mathrm{~mm}^{2}$ for male and $337 \pm 140 \mathrm{~mm}^{2}$ for female subjects. ${ }^{64}$

A few studies ${ }^{48,58,67,117,144}$ specified that, when the manikin was sitting or standing upright, the two jets from the nostrils were declined $45^{\circ}$ downward from the horizontal plane and $30^{\circ}$ from each other. Expiratory flows from the mouth were normally specified to be in a horizontal direction. These directions of expiratory jets were supported by some of previous human subject studies, ${ }^{146-147}$ although measurements by Gupta et al. ${ }^{63}$ indicated that jets from the nostrils were declined $60 \pm 6^{\circ}$ downwards and $42 \pm 16^{\circ}$ from each other. In addition,

Gupta et al. ${ }^{64}$ found that the coughing jet from the mouth was declined nearly $30^{\circ}$ downwards from the horizontal plane, which differs radically from the widely assumed horizontal direction.

This article is protected by copyright. All rights reserved. 


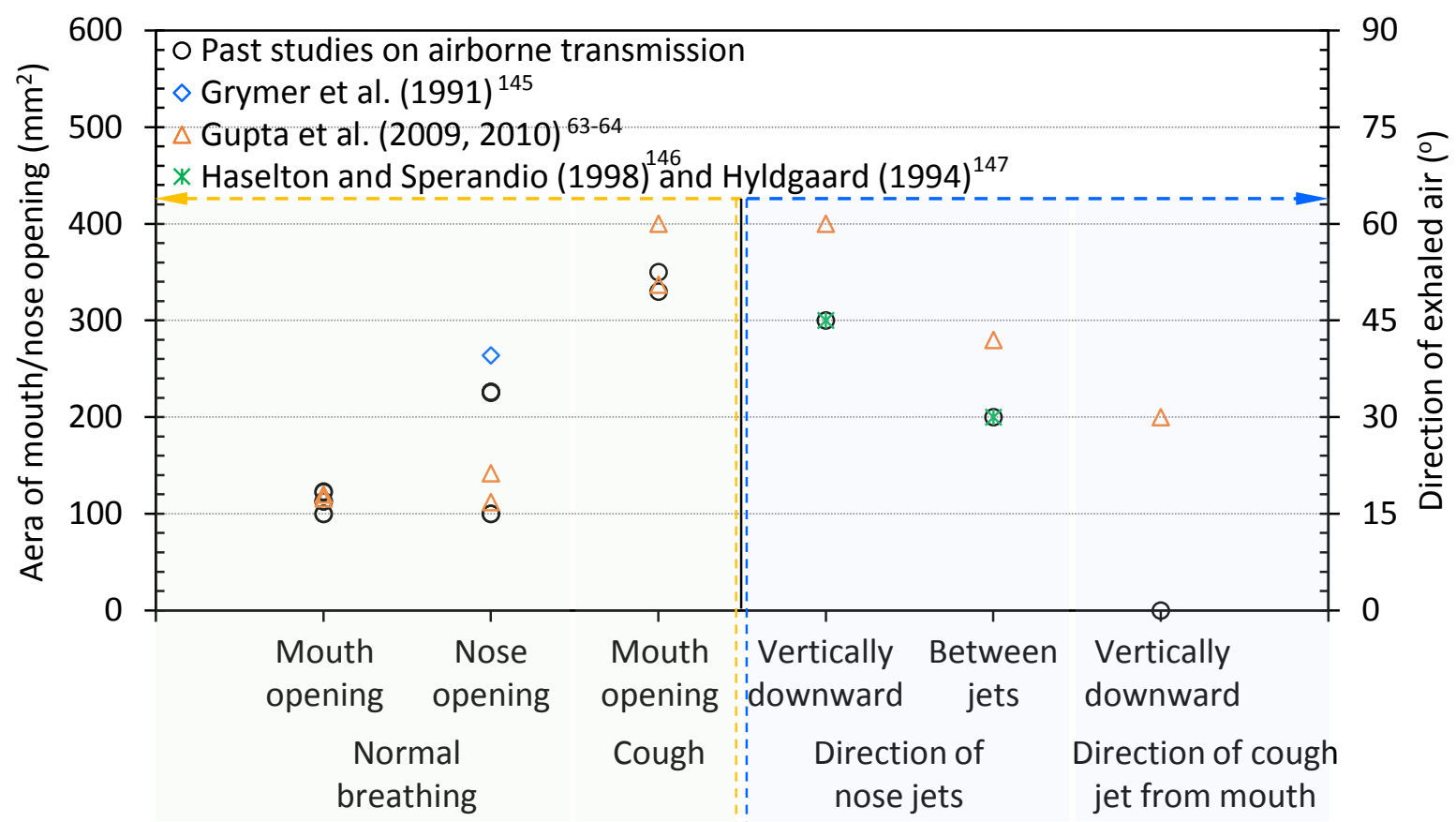

Figure 9 Comparison of the geometry of mouth and nose defined in previous studies of airborne transmission and those obtained from human subject studies; 'vertically downwards' indicates that the angle declined downwards from the horizontal plane and 'between jets' the angle between the two nose jets.

Figure 9 presents a comparison of mouth and nose geometry as defined in previous studies of airborne transmission and those obtained from human subjects. Except for the mouth opening area, the large differences between previous manikin studies and human subject data and between different human subject studies are apparent. The different results obtained from the limited number of human subject studies are probably due to differences in both experimental subjects and instrumentation. More human subject studies are required. Based on human subject studies, it will be necessary to define standard mouth and nose geometries for breathing thermal manikins, ${ }^{65-66}$ which would make possible cross comparisons between different studies.

This article is protected by copyright. All rights reserved. 
Table 1 Summary of the geometry of the mouth and nose, characteristics of the breathing flow and the expiratory medium as defined in previous studies of airborne transmission.

\begin{tabular}{|c|c|c|c|c|c|c|c|c|c|c|c|}
\hline \multirow{2}{*}{ References } & \multicolumn{5}{|c|}{ Exposed manikin } & \multicolumn{6}{|c|}{ Infected manikin } \\
\hline & $\begin{array}{l}\text { Geometry } \\
\text { of mouth }\end{array}$ & $\begin{array}{l}\text { Geometry } \\
\text { of nose }\end{array}$ & $\begin{array}{l}\text { Pulmonary } \\
\text { rate }(\mathrm{L} / \mathrm{min})\end{array}$ & $\begin{array}{l}\text { Breathing } \\
\text { frequency } \\
\text { (times/min) }\end{array}$ & $\begin{array}{l}\text { Breathing } \\
\text { temperature ( } \\
\left.{ }^{\circ} \mathrm{C}\right)\end{array}$ & $\begin{array}{l}\text { Geometry of } \\
\text { mouth }\end{array}$ & $\begin{array}{l}\text { Geometry } \\
\text { of nose }\end{array}$ & $\begin{array}{l}\text { Pulmonary } \\
\text { rate }(\mathrm{L} / \mathrm{min})\end{array}$ & $\begin{array}{l}\text { Breathing } \\
\text { frequency } \\
\text { (times/min) }\end{array}$ & $\begin{array}{l}\text { Breathing } \\
\text { temperature }( \\
\left.{ }^{\circ} \mathrm{C}\right)\end{array}$ & $\begin{array}{l}\text { Expiratory } \\
\text { medium }\end{array}$ \\
\hline $\begin{array}{l}\text { Yang et al., } \\
2016^{80}\end{array}$ & & & & & 32 & & & & & 32 & \\
\hline $\begin{array}{l}\text { Villafruela } \\
\text { et al., } 2016^{48}\end{array}$ & $\begin{array}{l}\text { Semi- } \\
\text { ellipsoid } \\
\text { shape: } 123 \\
\mathrm{~mm}^{2}\end{array}$ & & 9.9 & 15 & & $\begin{array}{l}\text { Semi- } \\
\text { ellipsoid } \\
\text { shape: } 123 \\
\mathrm{~mm}^{2}\end{array}$ & & 11.34 & 19.9 & & $\mathrm{~N}_{2} \mathrm{O}, 2.7 \%$ \\
\hline $\begin{array}{l}\text { Villafruela } \\
\text { et al., } 2016 \\
(C F D)^{48}\end{array}$ & $122 \mathrm{~mm}^{2}$ & $225 \mathrm{~mm}^{2}$ & 9.9 & 15 & 34 & $122 \mathrm{~mm}^{2}$ & $225 \mathrm{~mm}^{2}$ & 11.4 & 20 & 34 & \\
\hline $\begin{array}{l}\text { Liu et al., } \\
2016^{119}\end{array}$ & $100 \mathrm{~mm}^{2}$ & $100 \mathrm{~mm}^{2}$ & 10 & 15 & & $100 \mathrm{~mm}^{2}$ & $100 \mathrm{~mm}^{2}$ & 11.0 & 15 & & $\mathrm{~N}_{2} \mathrm{O}, 4 \%$ \\
\hline $\begin{array}{l}\text { Yang et al., } \\
2015^{89,107}\end{array}$ & & & & & & & & 8.4 & 10 & 34 & $\mathrm{~N}_{2} \mathrm{O}$ \\
\hline $\begin{array}{l}\text { Lipczynska } \\
\text { et al., } \\
2015^{103}\end{array}$ & & & & & & & & 6 & & & $\mathrm{SF}_{6}$ \\
\hline $\begin{array}{l}\text { Bolashikov } \\
\text { et al., } 2015^{57}\end{array}$ & & & & & & & & 6 & & 38 & $\begin{array}{l}\mathrm{R} 134 \mathrm{a}, 252 \\
\mathrm{mg} / \mathrm{min}\end{array}$ \\
\hline $\begin{array}{l}\text { Cao et al., } \\
2015^{148}\end{array}$ & $123 \mathrm{~mm}^{2}$ & & 8.8 & 16 & & $123 \mathrm{~mm}^{2}$ & & 8.8 & 16 & & $\mathrm{~N}_{2} \mathrm{O}$ \\
\hline $\begin{array}{l}\text { Olmedo et } \\
\text { al., } 2013^{100}\end{array}$ & $\begin{array}{l}\text { Circular } \\
\text { shape, } 100 \\
\mathrm{~mm}^{2}\end{array}$ & & 6.6 & 10 & $34 \pm 1$ & $\begin{array}{l}\text { Semi- } \\
\text { ellipsoid } \\
\text { shape, } 123 \\
\mathrm{~mm}^{2}\end{array}$ & & 10.95 & 14.6 & $34 \pm 1$ & $\mathrm{~N}_{2} \mathrm{O}$ \\
\hline $\begin{array}{l}\text { Melikov and } \\
\text { Dzhartov, } \\
2013^{111}\end{array}$ & & & 6 & 10 & 34 & & & 6 & 10 & 34 & R134a \\
\hline $\begin{array}{l}\text { Li et al., } \\
2013^{81}\end{array}$ & & & 8.4 & & & & & 8.4 & & 35 & $\begin{array}{l}\text { Particles: } 1,5 \text {, } \\
10 \mu \mathrm{m} \text { and gas }\end{array}$ \\
\hline $\begin{array}{l}\text { Bolashikov } \\
\text { et al., } \\
2013^{115}\end{array}$ & & & & & & & & 6 & & & $\mathrm{R} 134 \mathrm{a}$ \\
\hline $\begin{array}{l}\text { Olmedo et } \\
\text { al., } 2012^{116}\end{array}$ & $\begin{array}{l}\text { Circular } \\
\text { shape, } 113 \\
\mathrm{~mm}^{2}\end{array}$ & $\begin{array}{l}\text { Circular } \\
\text { shape, } 226 \\
\mathrm{~mm}^{2}\end{array}$ & 9.9 & 15 & $34 \pm 0.5$ & $\begin{array}{l}\text { Semi- } \\
\text { ellipsoid } \\
\text { shape, } 123 \\
\mathrm{~mm}^{2}\end{array}$ & $\begin{array}{l}\text { Circular } \\
\text { shape, } 226 \\
\mathrm{~mm}^{2}\end{array}$ & 10.83 & 19 & $34 \pm 0.5$ & $\begin{array}{l}\mathrm{N}_{2} \mathrm{O}, 0.3 \\
\mathrm{~L} / \mathrm{min}\end{array}$ \\
\hline $\begin{array}{l}\text { Nielsen et } \\
\text { al., } 2012^{95}\end{array}$ & $\begin{array}{l}\text { Circular } \\
\text { shape, } 113 \\
\mathrm{~mm}^{2}\end{array}$ & & 10 & 15.5 & 34 & $\begin{array}{l}\text { Semi- } \\
\text { ellipsoid } \\
\text { shape, } 123 \\
\mathrm{~mm}^{2}\end{array}$ & & 11 & 19 & 34 & $\begin{array}{l}\mathrm{N}_{2} \mathrm{O}, 0.3 \\
\mathrm{~L} / \mathrm{min}\end{array}$ \\
\hline $\begin{array}{l}\text { Bolashikov } \\
\text { et al., } 2012^{54}\end{array}$ & & & & & & $\begin{array}{l}\text { Circular } \\
\text { shape, } 346 \\
\mathrm{~mm}^{2}\end{array}$ & & & & & \\
\hline $\begin{array}{l}\text { Poon and } \\
\text { Lai, } 2011^{78}\end{array}$ & & & 7,15 and 23 & 15 & & & & & & & \\
\hline $\begin{array}{l}\text { Melikov et } \\
\text { al., } 2011^{109}\end{array}$ & & & & & & & & 14.4 & & 38.6 & R134a \\
\hline $\begin{array}{l}\text { Li et al., } \\
2011^{90}\end{array}$ & & & 8.4 & & 35 & & & 8.4 & & 35 & \\
\hline $\begin{array}{l}\text { Nielsen et } \\
\text { al., } 2010^{52}\end{array}$ & & & & & & & & 6.22 & 9.76 & 34 & $\mathrm{~N}_{2} \mathrm{O}, 0.4 \mathrm{~L} / \mathrm{s}$ \\
\hline Rim and & & & & 12 & & & & & & & Particles, 0.03, \\
\hline $\begin{array}{l}\text { Novoselac, } \\
2009^{61}\end{array}$ & & & & & & & & & & & $\begin{array}{l}0.77 \text { and } 3.2 \\
\mu \mathrm{m}, 1050 \\
\mathrm{~kg} / \mathrm{m}^{3} ; \mathrm{SF}_{6} \text {, } \\
0.1 \%\end{array}$ \\
\hline $\begin{array}{l}\text { Pantelic et } \\
\text { al., } 2009^{68}\end{array}$ & & & 6 & 10 & 34 & & & & & & \\
\hline $\begin{array}{l}\text { Qian et al., } \\
2008^{101}\end{array}$ & & & 6 & 10 & & $\begin{array}{l}\text { Semi- } \\
\text { ellipsoid } \\
\text { shape, } 123 \\
\mathrm{~mm}^{2}\end{array}$ & $\begin{array}{l}\text { Circular } \\
\text { shape, } 226 \\
\mathrm{~mm}^{2}\end{array}$ & 6 & 10 & $\begin{array}{l}32 \text { from nose } \\
\text { and } 34 \text { from } \\
\text { mouth }\end{array}$ & $\mathrm{N}_{2} \mathrm{O}$ \\
\hline $\begin{array}{l}\text { Nielsen et } \\
\text { al., } 2008^{121}\end{array}$ & & & & & & & & 18 & 12 & & \\
\hline $\begin{array}{l}\text { Gao and } \\
\text { Niu, } 2007^{149}\end{array}$ & & & 8.4 & & & & & & & & $\begin{array}{l}\text { Particles, } 1,5 \text {, } \\
10 \mu \mathrm{m} \text { and } \\
\mathrm{CO}_{2}\end{array}$ \\
\hline
\end{tabular}


Zhu et al., $\quad 350 \mathrm{~mm}^{2} \quad 330 \mathrm{~mm}^{2} \quad 24$

$2006^{82}$

Qian et al.

$2006^{92}$

Gao and

Niu, $2006^{83}$

Cermak et Ellipsoid Circular 6

al., $2006^{58}$

shape: 25 shape, 100

mm width $\mathrm{mm}^{2}$

and $5 \mathrm{~mm}$

Bjørn and

Nielsen,

$2002^{117}$

Brohus and

height

$350 \mathrm{~mm}^{2} \quad 330 \mathrm{~mm}^{2}$

10

Circular 6

shape, 226

$\mathrm{mm}^{2}$

Circular

shape, 226

$\mathrm{mm}^{2}$

$\begin{array}{lll}6 & 10 & 32 \text { nose and } \mathrm{NO}_{2} \\ & 34 \text { from } \\ \text { mouth }\end{array}$

mouth

34

Circular 6

$\mathrm{SF}_{6}$

$\begin{array}{ll}\text { Ellipsoid } & \text { Circular } \\ \text { shape: } 25 & \text { shape, } 100\end{array}$

mm width $\mathrm{mm}^{2}$

and $5 \mathrm{~mm}$

33-34 from

mouth and 32-

33 from nose height

Circular 6

shape, 226

$\mathrm{mm}^{2}$

Circular

shape, 226

$\mathrm{mm}^{2}$

1

\subsection{Breathing mode}

The most widely investigated breathing mode in previous studies, for both the infected and exposed individual, was 'exhalation through mouth and inhalation through nose' ${ }^{48,57,89,92,100,111}$ A number of studies were carried out using the 'non-breathing' mode for the exposed manikin. ${ }^{103,107,109,115}$ Most CFD studies simulated an 'inhalation only' mode for the exposed manikin ${ }^{81,82,90,119}$ and an 'exhalation only' mode for the infected manikin. ${ }^{48,80,83,119}$ However, as reviewed and discussed in section 2.5, these unrealistic breathing modes will have biased the predicted cross-infection risks and so should be discounted.

A sinusoidal cycle ' $2.5 \mathrm{~s}$ inhalation $+2.5 \mathrm{~s}$ exhalation $+1 \mathrm{~s}$ break' was the most widely used. ${ }^{57,89,103,107}$ However, many studies used a cycle without a break, such as ' $2+2$ s'. ${ }^{78,80,119}$ As discussed above, the break between exhalation and inhalation would influence the measured exposure, ${ }^{122}$ and this should thus not be ignored. CFD studies simulating 'exhalation only' or 'inhalation only' assumed a steady and constant breathing flow rate. ${ }^{81-}$ 83,90,150,151 Although some human subject tests have been conducted to measure the characteristics of a natural breathing flow, ${ }^{152-153}$ they were carried out for medical 
applications and no quantification of the evolution of the breathing flow rate over time was obtained. Based on human subject studies, Gupta et al. ${ }^{63}$ reported recently that the variation of the breathing flow rate takes an approximately sinusoidal form.

\subsection{Characteristics of breathing flow}

Table 1 summarizes the characteristics of breathing flow assumed in previous studies, including the pulmonary ventilation rate, the breathing frequency, and the temperature of the expiratory flow. In general, pulmonary ventilation rates from 6.0 to $10.0 \mathrm{~L} / \mathrm{min}$ were widely used to simulate light activities in sitting and standing postures. A breathing frequency of 10.0 times/min was usually used for a pulmonary ventilation rate of $6.0 \mathrm{~L} / \mathrm{min}$, and 15.0 times/min for $10.0 \mathrm{~L} / \mathrm{min}$. In fact, both pulmonary rate and breathing frequency depend on many physiological factors, such as body size, metabolic rate, gender and age. ${ }^{142}$ However, the influence of pulmonary rate and breathing frequency on the risk of cross-infection during other breathing activities has rarely been investigated.

The temperature of the expiratory flow was usually specified to be $34{ }^{\circ} \mathrm{C}$. In some studies the expiratory air were heated to $38{ }^{\circ} \mathrm{C}$ in order to achieve the same density as expiratory flows having high humidity. ${ }^{57-58,83,104,109}$ An earlier human subject study ${ }^{154}$ found that the temperature of the expiratory flow varies largely with the ambient air temperature, and the temperature from both mouth and nose is approximately $34{ }^{\circ} \mathrm{C}$ at an ambient temperature of $23{ }^{\circ} \mathrm{C}$.

Only a few reports stated the speed of the expiratory flow for normal breathing, which was $3.0 \mathrm{~m} / \mathrm{s}$ (at peak) from the nose, ${ }^{80} 2.0-3.0 \mathrm{~m} / \mathrm{s}$ (at peak) from the mouth, ${ }^{67} 4.74 \mathrm{~m} / \mathrm{s}$ (at peak) from the mouth ${ }^{116}$ and $2.67 \mathrm{~m} / \mathrm{s}$ (averaged) ${ }^{121}$. These expiratory values were much higher 
than those reported from human subject studies, where the peak speed during normal breathing was approximately 1-2 m/s..$^{47,147,155-156}$ This difference implies an inaccurate definition of either pulmonary rate or mouth/nose opening area. In addition, human subject studies indicated that the expiratory speed could be as much as $16.0 \mathrm{~m} / \mathrm{s}$ during speech, ${ }^{23}$ but was on average $2.3-4.1 \mathrm{~m} / \mathrm{s}$ while speaking. ${ }^{22,157}$ With such speeds, the expiratory jets could project droplets typically up to $1.0 \mathrm{~m}$ for normal breathing and several meters for coughing and sneezing. ${ }^{24-25,42}$ Note that the dynamics of the inhalation flow very close to the mouth and nose are similar. ${ }^{146,158}$

This article is protected by copyright. All rights reserved. 
Table 2 Summary of the characteristics of a cough/sneeze as defined in previous studies of airborne transmission.

\begin{tabular}{|c|c|c|c|c|}
\hline Reference & $\begin{array}{l}\text { Cough/sneeze rate and } \\
\text { frequency }\end{array}$ & Cough medium & $\begin{array}{l}\text { Cough } \\
\text { duration }(\mathrm{s})\end{array}$ & $\begin{array}{l}\text { Cough } \\
\text { speed }(\mathrm{m} / \mathrm{s})\end{array}$ \\
\hline Yang et al., $2016^{80}$ & & $\begin{array}{l}\text { Water, volatile fraction } 98.2 \%, 10 \\
\text { and } 100 \mu \mathrm{m} \text {; gas }\end{array}$ & & 10 \\
\hline Liu et al., $2016^{119}$ & & $\mathrm{~N}_{2} \mathrm{O}, 4 \%$ & & \\
\hline \multirow[t]{3}{*}{$\begin{array}{l}\text { Pantelic et al., } 2015^{69} \\
\text { Pantelic and Tham, } 2013^{55}\end{array}$} & $1.4 \mathrm{~L} /$ cough; & Water $90 \%$ and glycerin $10 \%$ & 0.5 & \\
\hline & Once/90 s; & & & \\
\hline & 20 coughs/location & & & \\
\hline Licina et al., $2015^{62}$ & & $\begin{array}{l}\text { Water } 94 \% \text { and glycerin } 6 \%, 0.5- \\
0.65 \mu \mathrm{m}\end{array}$ & & 10 \\
\hline Cao et al., $2015^{161}$ & $1.4 \mathrm{~L} /$ cough & Particles, $0.77 \mu \mathrm{m}$ & 1 & 6 \\
\hline Melikov et al., $2012^{118}$ & $\begin{array}{l}\text { Peak } 14 \pm 1.7 \mathrm{~L} / \mathrm{s} \text {, totally } \\
1.9 \pm 0.1 \mathrm{~L} / \text { cough, }\end{array}$ & $\mathrm{CO}_{2}, 100 \%$ & 0.55 & 52 \\
\hline & $15-20$ coughs for average & & & \\
\hline Bolashikov et al., $2012^{54,108}$ & $\begin{array}{l}\text { Peak: } 10 \mathrm{~L} / \mathrm{s} \text {, totally } 2.5 \\
\text { L/cough, } 15-20 \text { coughs for } \\
\text { average }\end{array}$ & $\mathrm{CO}_{2}, 100 \%$ & 0.5 & 28.9 \\
\hline Poon and Lai, $2011^{78}$ & & $\mathrm{NaCl}$ solution, $0.01-0.2 \mu \mathrm{m}$ & & 15,30 \\
\hline (sneeze) & & & & \\
\hline Li et al., $2011^{90}$ & $4.8 \mathrm{~L} / \mathrm{s}$ & Particles, $1-10 \mu \mathrm{m}$ & 0.5 & 22 \\
\hline Pantelic et al., $2009^{68}$ & $0.4 \mathrm{~L} / \mathrm{s}$ & Water $94 \%$ and glycerin $6 \%$ & 1 & 10 \\
\hline Zhu et al., $2006^{82}$ & & Particles, $30-500 \mu \mathrm{m}$ & & 11.2 \\
\hline $\begin{array}{l}\text { Gao and Niu, } 2006^{83} \\
\text { (sneeze) }\end{array}$ & $4.17 \mathrm{~L} / \mathrm{s}$ & Gas, $1000 \mathrm{ppm}$ & & \\
\hline
\end{tabular}

\subsection{Coughing and sneezing}

Compared to normal breathing, coughing and sneezing flows have a higher concentration of droplets ${ }^{23}$ but a lower event duration and a lower event frequency. Table 2 summarizes the characteristics of a cough and a sneeze as defined in previous studies of airborne transmission. Few of these studies provided a detailed evolution of the cough/sneeze flow rate over time. Melikov and his colleagues ${ }^{54,108,118}$ used the peak rates as $14 \mathrm{~L} / \mathrm{s}$ and $10 \mathrm{~L} / \mathrm{s}$ in 
their studies. The duration of each cough was often specified as $0.5 \mathrm{~s}, 0.55 \mathrm{~s}$ or $1.0 \mathrm{~s}$. Overall, the total flow volume for a cough was usually stated to be around 1.4-2.5 L. The cough flow volume obtained in human subject studies varied largely between different studies, including 0.8-2.2 L with an average of $1.4 \mathrm{~L}^{82}$ up to $5.0 \mathrm{~L}$ with an average of $3.0 \mathrm{~L}^{159}$ and $0.4-1.6 \mathrm{~L}$ for male and $0.25-1.25 \mathrm{~L}$ for female subjects ${ }^{64}$.

The speeds of coughing flows reported in previous studies of airborne transmission were usually between 6.0 and $52.0 \mathrm{~m} / \mathrm{s}$, even though some of these were average values and some were peak values. A similarly large difference is to be found in the reports of human subject studies. Tang et al. ${ }^{160}$ found that the peak coughing speed was $5.0 \mathrm{~m} / \mathrm{s}$, which was very similar to the peak sneezing speed of $4.5 \mathrm{~m} / \mathrm{s} .{ }^{155}$ Some other studies reported a much higher peak coughing speed of $6-22 \mathrm{~m} / \mathrm{s}$ (> $10 \mathrm{~m} / \mathrm{s}$ on average),${ }^{22,64,82,156-157}$ and even a very high sneezing speed, up to $100 \mathrm{~m} / \mathrm{s}^{24-25}$

It should be noted that the flow rate and mouth opening area during a cough are highly time dependent. The cough flow rate over time usually follows a combination of gamma probability distribution functions. ${ }^{64}$ Due to the limited number of human subject studies and their highly different results, most previous studies of airborne transmission did not accurately simulate cough/sneeze characteristics. In addition, the horizontal direction of cough/sneeze flows that was widely assumed in previous studies may not be common in practice. ${ }^{64}$ Poon and $\mathrm{Lai}^{78}$ indicated that an increase in the pulmonary ventilation rate can reduce personal exposure to an approaching sneezing flow, because the cleaning effect of the exhalation overwhelms the enhancing effect of the inhalation 


\subsection{Expiratory mediums}

Table 1 shows a summary of the expiratory mediums of infected individuals that were used in previous studies of airborne transmission, as a basis for the following observations.

Most studies used a tracer gas or a mixture of tracer gas and air to simulate the expiratory flows. The most widely used gases included $\mathrm{N}_{2} \mathrm{O}, \mathrm{SF}_{6}, \mathrm{R} 134 \mathrm{a}$ and $\mathrm{CO}_{2}$, which all have the general advantages of a tracer gas. ${ }^{162-163}$ The rationale for using tracer gas to simulate expiratory droplet nuclei assumes that a significant proportion of the expiratory droplet nuclei is smaller than $2-3 \mu \mathrm{m}$ in diameter ${ }^{22,27,28,30,33}$ and that such fine particles behave very like gas. ${ }^{124-127,149}$ Some studies did work with particles. Relatively small particles in the range 0$10 \mu \mathrm{m}$ in diameter were usually investigated, mainly because this is the dominant range of expiratory droplet nuclei for almost all breathing activities. ${ }^{36,164}$

Most studies defined the concentration of expiratory mediums, but few explained the reasoning behind their particular definition (e.g., $2.7 \%$ of $\mathrm{N}_{2} \mathrm{O}$ ). Generally, in mouth exhalation, nose exhalation, coughing and talking, coughing produces the largest droplet concentrations ${ }^{166}$ and nose exhalation the least. ${ }^{27}$ In addition, droplet concentration can be influenced by other factors, such as body weight, gender and age. ${ }^{167-169}$ To the best of the author's knowledge, the influence of concentration on the risk of cross-infection has not yet been investigated. In addition, the survival of pathogens in the indoor environments was influenced by many factors, including particularly the air humidity. The survival time is an important factor determining the risk of cross-infection. However, the comparison of the survival of the exhaled pathogens and the time constants of ventilation systems was rarely carried out in past studies.

This article is protected by copyright. All rights reserved. 


\section{Experimental and CFD techniques}

The following sections summarize the most widely used experimental and CFD techniques in previous studies and discuss the factors that may influence the reliability of estimates of airborne transmission.

\subsection{Thermal manikins}

A thermal manikin is an advanced experimental facility used to investigate airborne transmission. ${ }^{57,61,69,95,100,103,107,170-171}$ Owing to its accurate geometry and close-to-human thermal and breathing characteristics, a thermal manikin makes reliable modelling of airborne transmission possible. ${ }^{65-66}$ Thermal manikins used in previous studies of airborne transmission had 17-26 body segments, all of which could be heated and individually controlled to maintain a surface temperature equal to the skin temperature of an average human being in thermal comfort. The breathing process was simulated with additional artificial lungs. Note that dummy(s) were also frequently used together with manikins in many studies. ${ }^{54,57,108,111,115}$ Compared to thermal manikins, dummies have less accurate geometries, do not have the accurate mouth and nose openings to simulate breathing activities, and cannot simulate the human body surface temperature in comfort state. The detailed comparisons of various simplified body geometries and the generated thermal plumes can be found in references. ${ }^{172-175}$

Two important factors in the use of thermal manikins are proper dosing of the expiratory medium from the infected manikin and accurate sampling of the medium inhaled by the exposed manikin. The best dosing approach is to dose through the breathing system of a thermal manikin, rather than to dose through a separate machine. For tracer gas, this is relatively convenient and has been widely used in previous studies. However, few studies 
have successfully dosed aerosols through the breathing system of a thermal manikin and a separate generator for aerosols was generally used. The authors' experience of the integration of an aerosol generator into the breathing system of manikin indicates that the breathing system can easily become blocked by the aerosols, due to the narrow 'respiratory tract' and the low expiratory speed. Regarding sampling, many past studies did not provide an accurate sampling location. Melikov and his colleagues ${ }^{54,57,108,109,115,118}$ defined their sampling locations, which were usually at $5 \mathrm{~mm}$, or less, away from the mouth. Some studies reported their sampling locations as $10 \mathrm{~mm}$ or above away from the mouth. ${ }^{55,61,68,69,176}$ Sensitivity studies conducted by Melikov and Kaczmarczyk ${ }^{66}$ suggested that accurate measurements of inhalation can be obtained if the sampling location is at the upper lip with a distance of less than $10 \mathrm{~mm}$ from the face. However, a recent study by Bivolarova et al ${ }^{122}$ indicated that the location of the pollutant source is important; the measurements should be performed in inhaled air if the pollutants are located close to the breathing zone.

\subsection{Flow techniques}

The flow techniques used were Particle Image Velocimetry (PIV), smoke particles visualization and a Schlieren imaging technique. PIV is a commonly used technique for visualizing the instantaneous velocity field on a relevant plane across a breathing zone. ${ }^{59,68-}$ 70,102,177-180 The speed and direction of the target velocity field can be calculated accurately from the imaged seeding particles. The captured velocity field provides a clear indication of an exhalation jet and thus of the zone it affects in front of a thermal manikin. Smoke particles illuminated by a laser light sheet can also be used to visualize the expiratory flow plumes. ${ }^{71-72}$ This technique illustrates the movement of air, which, however, cannot quantitatively estimate the concentration of particles. The Schlieren imaging technique ${ }^{67,73-75,67,181}$ relies on temperature differences in the flow to refract a light beam and so visualize the expiratory 
flows. This technique does not use smoke particles or tracer gas, so it is suitable for work with human subjects. The two last-named approaches are convenient for comparing the efficiency of different infection control measures (such as masks and ventilation systems) and to evaluate their qualitative influence on airborne transmission. For instance, the visualized images obtained can indicate clearly how well a strong turbulent cough jet that penetrates forward and impinges on a nearby person can be stopped by wearing a mask. ${ }^{181-182}$ In general, flow techniques are limited to a relatively small measurement area in the breathing zone of one thermal manikin or person. Although they are useful for providing a straightforward understanding of expiratory flows, they provide no quantitative estimates of the risk of crossinfection.

\subsection{Tracer gas techniques}

Tracer gas techniques have been widely used to investigate airborne transmission between occupants (see also section 3.6). The cross-infection risk can be estimated quantitatively based on the measured tracer gas concentrations in the exhalation of the infected manikin and in the inhalation of the exposed manikin (see section 5). ${ }^{89,100,107,116,119,122}$ The main drawback of most tracer gas instruments is their long response time (of the order of 10-60 s), which largely exceed the scale of breathing activities (of the order of $1 \mathrm{~s}$ ). Such slow instruments are deficient in at least in two aspects. Firstly, it is impossible to investigate the dynamics of airborne transmission (see section 6.2). Secondly, even though steady-state measurements are acceptable, it may still be difficult to obtain an accurate time-averaged concentration for evaluating the risk of cross-infection (see section 5) for events with obvious time characteristics. In order to obtain a higher sampling rate, Melikov and his colleagues ${ }^{54,108,118}$ recently used a faster instrument (PS331) for sampling tracer gas, with a time constant of 0.8 
s and a sampling rate of $4 \mathrm{~Hz}$. This much faster approach is expected to improve our understanding of the dynamics of airborne transmission.

\subsection{Aerosol techniques}

Aerosol techniques have increasingly been used to investigate airborne transmission indoors. ${ }^{55,68,69,78,161,178}$ Several major aerosol dosing methods have been applied in recent studies. The Collison Nebulizer ${ }^{61}$ can generate monodisperse particles (of uniform size in the dispersed phase), which make it possible to examine the influence of particle size on airborne transmission. Most dosing methods ${ }^{178}$ generate a range of particle sizes simultaneously and it is not possible to discover the concentration distribution of each size bin. In addition, as discussed in section 4.1, there are technical problems with integrating aerosol generators into the breathing system of thermal manikins. Even if stand-alone particle generators are able to simulate breathing flows accurately, they cannot simulate the influence of occupants and their thermal boundary conditions, while a breathing thermal manikin can. The sampling rate of the aerosol instruments used in previous studies was $1 \mathrm{~Hz} .{ }^{69,161,178}$ Although this sampling rate is much higher than that of tracer gas monitors, it is still of the same order as the time scale of human breathing activities. In order to explore the dynamic process of airborne transmission, there is a need to develop still faster aerosol samplers. Another problem is that the presence of aerosol samplers could disturb the flow development, essentially because that they have to be placed relatively close to the sampling locations.

\subsection{Cough machines}

At least two cough machines were developed and used to investigate airborne transmission following a cough. The cough machine developed by the Technical University of Denmark $^{54,108,118}$ worked with tracer gas and was used together with a dummy. Another 
cough machine developed by the Hong Kong University of Science and Technology ${ }^{69}$ worked with aerosols (namely, a mixture of water and glycerin ${ }^{77}$ ), and was used separately, without a thermal manikin or dummy. Basically, a good cough machine should be able to simulate the most important cough characteristics, such as the varying cough flow rate over time and the proper mouth opening area. However, as shown in section 3.5, the simulated coughing characteristics in previous studies have been oversimplified when compared to the data obtained from human subjects. In order to improve our understanding of airborne transmission from a cough, more realistic, accurate and reliable cough machines that can work with tracer gas and/or aerosols will have to be developed.

\subsection{CFD techniques}

CFD studies usually employ computational thermal manikin(s) to investigate airborne transmission. The definition of the thermofluid boundary conditions of a computational thermal manikin was similar to that of a physical thermal manikin, except for two aspects. First, a uniform surface temperature was usually defined for a computational thermal manikin: $33{ }^{\circ} \mathrm{C}$ in Yang et al. ${ }^{80}$ and $31{ }^{\circ} \mathrm{C}$ in Gao and Niu ${ }^{83,149}$. Second, computational manikins used in past studies simulated nude bodies, as the effect of clothing was not considered. The presence of clothing could bring two effects. One is reduced surface temperature, which reduces the development of the CBL. Another is increased turbulent mixing. Licina et al. ${ }^{183}$ reported that loose clothing induces more turbulence than closely fitting clothing. How these effects of clothing influence exposure is still unclear.

CFD simulation of airborne transmission was limited to using the two-equation RANS turbulence models. ${ }^{84-85}$ However, the RANS turbulence models define turbulent fluxes in a time-averaged way, employing Reynolds isotropic decomposition and Boussinesq 
approximation $^{184}$, which are inherently incapable of capturing any dynamic flow characteristics $^{84}$ (see section 6.3 for detailed discussion).

\section{Evaluation methods}

A number of evaluation methods for the risk of cross-infection can be found in the literature. The concentration and the normalized concentration in the inhaled airflow of an exposed individual were most commonly used as an indicator of infection risk. ${ }^{48,51,55,57,61,78,80,82,95,100,111,116,119,149,161,176}$ In addition, Melikov et al. ${ }^{185}$ and Bolashikov et al. $^{54,108}$ proposed peak concentration level (PCL) and peak concentration time (PCT) to assess the exposure risk to a cough, where the former is defined as the maximum concentration in the inhaled airflow of an exposed individual after a cough and the latter is defined as the time at which the PCL is reached. Although the concentration is a useful indicator to compare different cases, it provides limited information for an evaluation of the risk of cross-infection. Based on the concentration field, some more accurate evaluation methods have been developed. Note that these evaluation methods were mostly developed based on the outbreak of infectious diseases and were thus widely used to evaluate epidemically the risk of crossinfection among a large group of people.

\subsection{Intake fraction}

Intake fraction $(I F)$ is defined as the proportion of exhaled pollutant mass from the infected individual that is inhaled by the exposed individual. ${ }^{186-187}$ It is called the rebreathed fraction in some studies. ${ }^{103}$ The intake fraction $\left(I F_{S}\right)$ can be expressed as:

$$
I F=\frac{C_{i} \cdot M_{h}}{C_{e} \cdot M_{e}}=\frac{\int_{0}^{t_{i}} C_{i}(t) M_{i} d t}{\int_{0}^{t e} C_{e}(t) M_{e} d t}
$$

This article is protected by copyright. All rights reserved. 
where $C_{i}$ is the inhaled pollutant concentration of the exposed individual, $C_{e}$ the exhaled pollutant concentration of the infected individual, $M_{i}$ and $M_{e}$ mass flow rates of inhaled airflow of the exposed individual and exhaled airflow of the infected individual, respectively, $C_{i}(t)$ and $C_{e}(t)$ the inhaled pollutant concentration of the exposed individual and the exhaled pollutant concentration of the infected individual at time $t$, respectively, $t_{i}$ and $t_{e}$ the exposure time of the exposed individual and the release time of the infected individual, respectively.

The intake fraction cannot reveal the influence of particle size or the viability and infectivity of any pathogen in the aerosol. In addition, the time-dependent model requires an accurate concentration profile over time, which can only be obtained from fast measurements. Even though the steady-state model is acceptable, it may still be difficult for slow measurements to provide an accurate estimate of the time-averaged concentration (see section 6.2) for events with obvious time characteristics.

\subsection{Wells-Riley model}

The well-known Wells-Riley model ${ }^{189}$ was developed to estimate the probability $(P)$ of airborne transmission of an infectious agent in the indoor environment.

$$
P=1-\exp \left(-\frac{I p q t_{0}}{Q}\right) d
$$

where $I$ is the number of infected individuals, $p$ the breathing rate per person, $q$ the quantum generation rate by an infected individual (quanta/s), $t_{0}$ the total exposure time, and $Q$ the supply rate of outdoor air. Note that a quantum means an infectious dose. This model has been widely applied to assess the risk of cross-infection by airborne transmission. However, 
as pointed out by Rudnick and Milton, ${ }^{190}$ this model assumes steady-state, complete-mixing conditions and requires the measurement of the outdoor air supply rate. Inaccurate or even unreasonable results are to be expected if these assumptions cannot be achieved. ${ }^{191}$ However, for airborne transmission where the exhaled pollutants from an infected individual can be regarded as a point source, concentration gradients would usually be established indoors, and the steady-state assumption would not be valid for short-term events.

\subsection{Reproductive number}

The reproductive number $\left(R_{A 0}\right)$ is the number of secondary infections that arise when a single infector is introduced into a population in a shared indoor environment, ${ }^{104,190}$ which is defined as:

$$
R_{A 0}=(n-1)\left[1-\exp \left(-\frac{\bar{f} q t_{0}}{n}\right)\right]
$$

where $n$ is the number of persons in a ventilated space and $\bar{f}$ the volume fraction of inhaled air that is exhaled by an infected individual, which is calculated as:

$$
\bar{f}=\frac{p}{Q}=\frac{C_{i}-C_{S}}{C_{e}}
$$

where $C_{S}$ is the concentration in the ventilation system supply airflow. In the original model by Rudnick and Milton ${ }^{190}, \mathrm{CO}_{2}$ generated by every person in a shared space is used as the expiratory air marker. For experiments using breathing thermal manikins, tracer gas simulating the exhaled flows can be used as an air marker. ${ }^{104}$ As for the Wells-Riley model, this model is based on the complete-mixing assumption. 
In some past studies, the risk of cross-infection was estimated according to an exponential dose-response model, which includes the major parameters that influence cross-infection risk. ${ }^{68,178,192-193}$ However, those parameters cannot be determined completely by engineering methods alone, as they also involve the medical and microbiological sciences.

\section{Discussions and future perspectives}

Previous sections reviewed our current understanding of airborne transmission between occupants in indoor environments and other related issues, where their limitations were discussed. Based on the literature review in previous sections, this section discusses further some important issues.

\subsection{Direction of indoor airflow pattern}

Although many studies have investigated the influence of ventilation method and supply airflow rate on airborne transmission, few studies considered the influence of the direction of the indoor airflow pattern. This is basically because that the indoor air speeds are mostly sufficiently small to be independent of direction. Some studies investigated the relative location of diffuser and exhaust grille in relation to the manikins in a hospital ward conditioned by DnV. ${ }^{100-101}$ They indicated that the risk of cross-infection and the removal efficiency of expiratory pollutants are both influenced considerably by the layout of diffuser and exhaust grilles. Their studies imply the importance of the direction of the indoor airflow pattern, although they did not analyse the influence of indoor airflow direction explicitly. Licina et al. ${ }^{102}$ investigated the influence of local uniform airflows on human exposure and reported that transverse flow from in front and from the side can effectively minimize or even eliminate exposure to pollutants from both the feet and a cough-simulated source in front, while an opposing flow from above can increase exposure to pollutants from the feet. This 
finding clearly demonstrates the importance of indoor airflow direction. Nevertheless, the findings of this study are limited to conditions with ideally uniform airflows.

The direction of the indoor airflow pattern is shaped mainly by the relative position of diffuser(s) and exhaust grille(s), which is especially important for ventilation systems with diffuser(s) and exhaust grille(s) on opposite sides of a room. Typical examples of air distribution methods that have an obvious local flow direction is PV and that have an obvious overall flow direction in the room is Stratum Ventilation $(\mathrm{SV})^{194}$, where the latter was proposed to use in warm regions to fulfil the requirement of elevated room air temperature. Figure 10 presents schematically two possible layouts of the occupants in relation to the flow direction when the SV is used. By analysing the two scenarios illustrated in Figure 10, it may be predicted that increasing the supply airflow rate could increase the cross-infection risk between an upstream infected person and a downstream exposed person (in Figure 10 (a)), but may help to decrease the risk for the reverse layout (in Figure 10 (b)). Similar to the situation of increasing $\mathrm{ACH}$ (see section 2.2), the flow with an obvious direction would have two effects to the spread of expiratory droplet nuclei: enhancing the dilution and increasing the dispersion. The counteracting effect of these two could be different, depending on whether the steady-state or the transient condition is considered. Here further studies are required.

In general, including the influence of the direction of the indoor airflow pattern may modify our current understanding of the relationship between cross-infection risk and the factors that affect it. In particular, the cross-infection risk may decrease more or less rapidly with the increase of the relative distance between the source and the exposed person when the indoor airflow direction changes. Systematic investigation is required in order to make clear the influence of the direction of the indoor airflow pattern. 

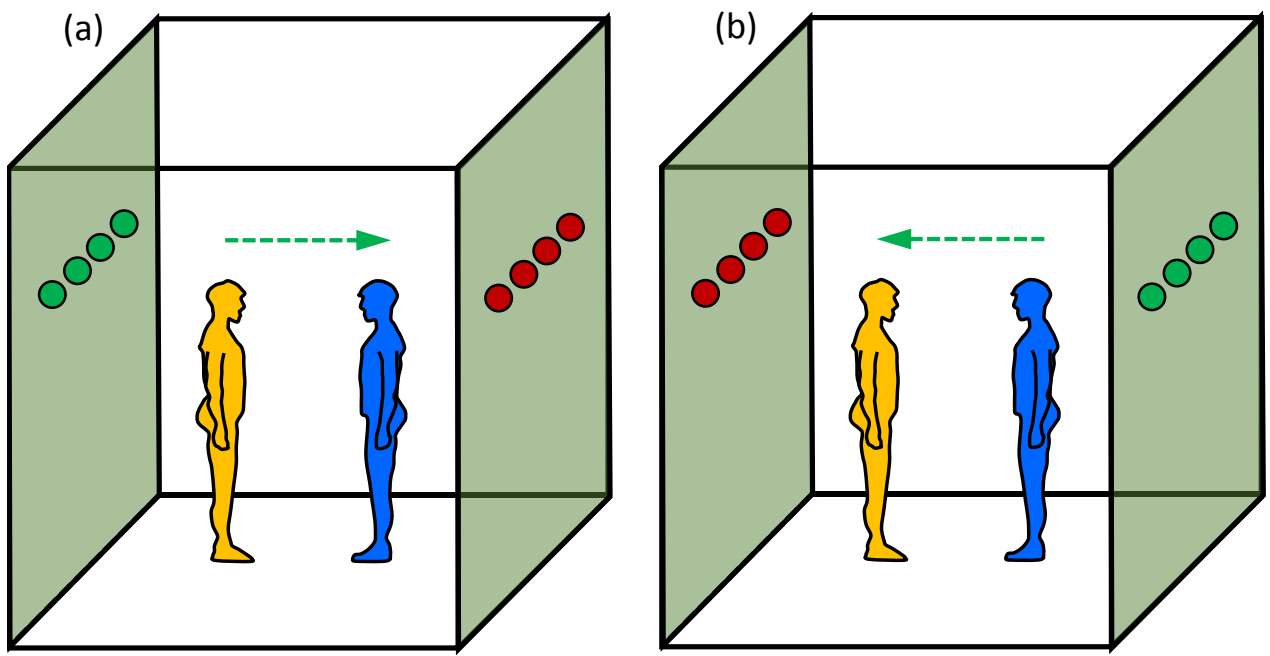

Figure 10 Schematic view of two possible layouts of the exposed and infected persons in relation to the direction of indoor airflow pattern when SV is used.
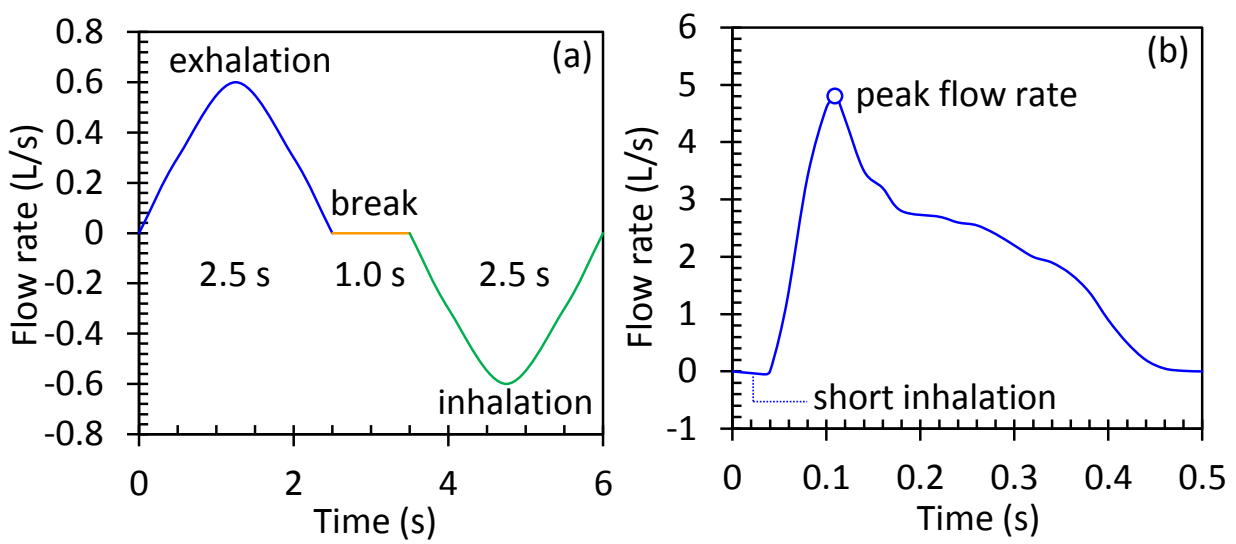

Figure 11 Fast breathing activities: (a) a normal breathing process and (b) a cough process.

\subsection{Dynamics of airborne transmission}

Human breathing activities are highly dynamic processes (see Figure 11 for examples). A typical breathing cycle includes $2.5 \mathrm{~s}$ inhalation, $2.5 \mathrm{~s}$ exhalation and $1 \mathrm{~s}$ break, which has a time scale of the order of $1 \mathrm{~s}$. It should be borne in mind that, within a breathing cycle, the infectious airflows from an infected individual are exhaled for only $2.5 \mathrm{~s}$ over a $6 \mathrm{~s}$ cycle, while for an exposed individual there is still only a $2.5 \mathrm{~s}$ inhalation of the infectious flows after the cleaning effect of a $2.5 \mathrm{~s}$ exhalation and a $1 \mathrm{~s}$ break. In order to improve the estimate 
of the risk of cross-infection, it is important to accurately distinguish and measure the $2.5 \mathrm{~s}$ exhaled concentration of an infected individual and the $2.5 \mathrm{~s}$ inhaled concentration of an exposed individual. The expiratory process for a cough and a sneeze is even more dynamic, considering their short duration, uncertain frequency and highly varying flow rate (see Figure $11(b))$

Together with the interaction with the human body thermal plume and a turbulent ventilation flow, dynamic breathing activities are difficult for existing slow instruments to follow, considering their long response times, which are of the order of at least $10 \mathrm{~s}$ for tracer gas and $1 \mathrm{~s}$ for particles (see sections 4.3 and 4.4 for details). Because of this, previous studies using tracer gas techniques were mostly performed under steady-state conditions, and thus only time-averaged results were obtained. In addition, the peak values during inhalations cannot be captured by such slow instruments, although they are very important for the evaluation of exposure risk.

For a certain type of infectious disease, the risk of cross-infection is determined by the exposed dose, which includes both exposed concentration and period. With a high exposed concentration, even a very short exposed period might be sufficient to accumulate a dose that could cause infection. Accurate sampling of the exposed concentration over time is especially important for short-term events with obvious time characteristics, such as a doctor visiting a hospital ward and a doctor consultation. In addition, it is meaningful to compare the time scale required to accumulate a dose and the survival time of a certain pathogen, so as to formulate more effective intervention measures. If the survival time is shorter than the time scale needed to accumulate a dose, no cross transmission would occur. However, all these time related processes can only be investigated in detail by using fast measurements or simulations.

This article is protected by copyright. All rights reserved. 
For two closely positioned persons, the direct exposure time is sometimes very short and a large amount of the infectious flow dissipates into the room. It is possible that part of this dissipated infectious flow will be transported by the circulating room air back to the breathing zone. The airborne transmission process must therefore be divided into two stages, namely a primary direct exposure stage and a secondary indirect exposure stage. This two-stage exposure might be especially worthy of separate investigation when evaluating the performance of some control measures, such as face masks and PV. Evidently, these control measures can effectively avoid the high-concentration direct exposure, but the secondary indirect exposure may still be sufficient to cause infection. ${ }^{90,148}$ In general, in order to understand the whole transmission process and the role of direct and indirect transmissions, transient studies will be required. In addition, human movements introduce obvious time characteristics to airborne transmission (see section 2.7), where transient studies would help improve current understanding.

\subsection{Application of CFD simulations}

Chamber experiment has so far been the dominant research technique for investigating airborne transmission indoors. There is no doubt about the importance of experimental measurements. However, an important disadvantage of chamber experiments is that measurements usually take place at only a few points. Although visualization techniques such as PIV and Schlieren imaging allow in principle 2D or even 3D velocity fields to be obtained, they cannot provide a quantitative evaluation of the cross-infection risks. Another disadvantage that has been mentioned above is the limitation of current experimental techniques, namely slow instruments for concentration measurement and weak integration of aerosol generators with thermal manikins. In addition, the presence of flow and concentration sensors near the mouth/nose of a thermal manikin may cause some flow disturbances. In 
addition, because thermal manikins are expensive, airborne transmission between multiple persons has rarely been investigated.

Numerical modelling with CFD can be a powerful alternative as it can avoid these limitations, although care is required for quality assurance. CFD simulation provides detailed information on relevant flow and concentration parameters in the whole computational domain. Such parameters can be generated in a very high temporal resolution, e.g., $0.01 \mathrm{~s}$, far less than the time scale of human breathing activities. Numerically, both tracer gas and aerosol can be generated accurately from the mouth/nose of an infected individual and then samples can be taken at the mouth/nose of an exposed individual. There are therefore no restrictions on the integration of dosing systems with manikins and no flow disturbance caused by physical instruments. In addition, CFD simulations have full control over the boundary conditions so parametric studies can be used to evaluate different cases. With these advantages, CFD is particularly suitable for the detailed investigation of the complex and dynamic flow interactions that take place in the breathing zones, especially when two individuals are positioned close together. It is also convenient for CFD to investigate airborne transmission between multiple persons in a same room, simply by including multiple computational thermal manikins.

However, an important matter of concern for CFD simulations is the predicted accuracy, ${ }^{195}$ which is influenced by geometrical oversimplification of the physical models, grid generation, specification of boundary conditions, and selection of methods of solution. Numerical and modelling errors can occur throughout these processes. The selection of a suitable turbulence model is very important to ensure acceptable accuracy of prediction. Zhang et al. ${ }^{196}$ reviewed published studies that compared some typical turbulence models 
used in simulating several different types of indoor air movement. In general, the $\mathrm{V}^{2}-\mathrm{f}$ model ${ }^{196-197}$ shows the overall best performance, followed by the large eddy simulation (LES) model $^{198}$. The most widely used RNG $k-\varepsilon$ model performs well for forced and mixed convection, but relatively underperforms for natural convection and strong buoyancy flow. However, in past studies, other turbulence models (except for RNG and standard $k-\varepsilon$ ) have rarely been used to investigate airborne transmission and thus their performance is still unknown.

Regarding CFD simulations of airborne transmission, an important issue is the large difference in spatial scales when breathing thermal manikin(s) are used. The dimensions of the ventilation openings (namely, diffuser and exhaust grille) are in the scales of $0.1-1.0 \mathrm{~m}$, whereas those of breathing organs (namely, mouth and nose) are of 0.001-0.01 m. In addition, air jets from diffusers and from breathing organs have large differences in speed, turbulence and temperature. It is important to accurately resolve both scales of flows simultaneously, which places a high demand on the turbulence model used. Such a large difference in scales also places high demands on the development of a high-resolution and high-quality computational grid, which means a relatively large number of cells and a high computational cost. Another issue is the accurate modelling of the dispersion of aerosols. Adherence to surfaces is the eventual fate of aerosols, and this is the most important cleaning mechanism for large aerosols. An accurate prediction of this fate is therefore important for accurate prediction of the risk of cross-infection. However, in the near-wall regions, the most widely-used RANS turbulence models using wall functions assume the same decomposition of flow variables along the normal-to-wall direction as along the other two directions. ${ }^{84,199}$ This assumption would apparently lead to an over-prediction of the deposition rate on walls. Again, more suitable turbulence models are still awaiting exploration. 
In order to guarantee the quality of CFD simulations, the general consensus on engineering practice is to have high-quality model verification and validation before any actual CFD studies are conducted. A systematic verification of various computational parameters, particularly the grid arrangement and the turbulence model, is an important step to ensure suitable selection. To the best of the authors' knowledge, these precautions have not been taken in past studies of airborne transmission. Model validation against high-quality experimental data is the final step to examine the quality of CFD simulations. However, most studies have validated their CFD models by using experiments with no breathing thermal manikins. The benchmark measurements for validating CFD models should include basically the measurement of the exposed concentration of a breathing thermal manikin located in a well-controlled climate chamber. On the other hand, because of slow instrumentation, there are no high-temporal-resolution experimental data that could be used to validate CFD models. Overall, while the use of CFD in engineering practice is becoming quite well established for ventilation applications, ${ }^{79,200-204}$ this is not yet the case for airborne transmission applications.

\section{Summary and conclusions}

This paper provides a review of published studies on airborne transmission between occupants in indoor environments. It is not intended to cover all past research efforts on this topic, but rather to focus on studies of the spread of expiratory agents from mouth/nose to mouth/nose for non-specific diseases. Four closely associated topics are covered, including the most important factors of the risk of cross-infection, the thermofluid boundary conditions of thermal manikins, research techniques and evaluation methods.

This article is protected by copyright. All rights reserved. 
Air distribution plays a significant role in influencing airborne transmission. However, some inconsistent findings have been obtained on the performance of various total volume ventilation methods. The excellent performance of PV and PE in reducing the risk of crossinfection has been widely documented. However, the use of PV to the infected individual can enhance the dispersion of expiratory flows and so should be avoided. The use of PE for the infected individual only is much better than PV for the healthy individual only. Increasing supply flow rate does not necessarily result in a decreased risk of cross-infection, because the expiratory agents are not uniformly distributed in a room and the flow interactions in the human microenvironment are not straightforward.

The relative distance between the infected and the exposed individuals is one of key factors determining the risk of cross-infection. Sufficient evidence indicates that the risk decreases sharply with the increase of distance up to a certain distance, namely $0.8-1.5 \mathrm{~m}$. In general, the flow interactions in the human microenvironment dominate airborne transmission over short distances $(<0.5 \mathrm{~m})$, while the general ventilation flow is more important over long distances $(>0.5 \mathrm{~m})$. The importance of the posture and orientation of individuals on airborne transmission is greater for short distances. Owing to the possible mutual penetration of breathing flows, face-to-face orientation results in the highest risk of cross-infection. The breathing function and mode must both be considered when investigating airborne transmission. In particular, the exhaled flow through the mouth of the infected individual can result in a high exposure risk for an exposed individual in front.

Owing to the limited number of human subject studies and the very varied results obtained, many assumptions and simplifications about the definition of the thermofluid boundary conditions of thermal manikins have had to be made. Although more human subject 
tests are required, a better exploitation of existing knowledge would allow an improved definition of the thermofluid boundary conditions. Most studies use tracer gases to simulate the expiratory mediums. Although some studies tend to support the use of tracer gas as a surrogate of small particles $(<2-3 \mu \mathrm{m})$, there is still no experimental evidence for the influence of particle size on the risk of cross-infection.

Tracer gas techniques provide a quantitative evaluation of airborne transmission, but are restricted by slow instrumentation (of the order of $>10 \mathrm{~s}$ ) and the fact that tracer gas is only representative of small particles. Aerosol techniques can closely model the transmission of expiratory droplet nuclei, but aerosol generators are seldom integrated with breathing thermal manikins. Aerosol instruments can sample relatively rapidly at $1 \mathrm{~Hz}$, i.e. at the same order as the time scale of breathing activities, but it is still impossible to investigate the dynamics of airborne transmission. CFD methods employing computational thermal manikins overcome these disadvantages, but quality assurance is a basic prerequisite and there are currently no high-temporal-resolution experimental data on airborne transmission for the model validation of transient CFD simulations.

Most studies use concentration (or its normalized form) measured in the breathing zone of an exposed individual to evaluate airborne transmission, although it provides only very limited information. Based on concentration profiles, other evaluation models have been developed, such as intake fraction, the Wells-Riley model, and Reproductive number. It should be noted that each model has its assumptions and applicable context. In particular, both the Wells-Riley model and Reproductive number are only valid if the complete-mixing assumption is true. In general, fast measurements are required to provide accurate concentration profiles for time-dependent evaluations, especially for short-term events. 
Overall, restricted by the limitations of existing research techniques and the limited knowledge of the thermofluid boundary conditions of human beings, the current understanding of airborne transmission indoors needs to be improved. In addition to the specific aspects summarized above, further attention should be paid to the following aspects.

- As ventilation flow is an important parameter governing airborne transmission, the direction of the indoor airflow pattern should be taken into account in future studies.

- Airborne transmission between occupants indoors is sometimes highly dynamic. In order to describe the dynamics, fast, transient, measurements/simulations are required.

- Further efforts should be made to extend the application of CFD in airborne transmission, and to improve the quality assurance.

\section{Acknowledgement}

The research leading to these results has received funding from the People Programme (Marie Curie Actions) of the European Union's Seventh Framework Programme (FP7/20072013) under REA grant agreement no. 609405 (COFUNDPostdocDTU). The authors would like to thank Prof. David Peter Wyon for his professional English language editing and technical suggestions.

\section{References}

1. Centers for Disease Control and Prevention (CDC). Guideline for Isolation Precautions: Preventing Transmission of Infectious Agents in Healthcare Settings, edited by Siegel JD, Rhinehart E, Jackson M, Chiarello L, The Healthcare Infection Control Practices Advisory Committee, Atlanta, GA: U.S. Department of Health and Human Services, 2007.

2. Centers for Disease Control and Prevention (CDC). Diseases \& Conditions. Atlanta, GA: U.S. Department of Health and Human Services available at: https://www.cdc.gov/DiseasesConditions, accessed on April 09, 2017.

3. Hodgson MJ, Miller SL, Li Y, et al. Airborne Infectious Diseases. ASHRAE Position Document, Atlanta, Georgia, 2012.

4. Clark RP, de Calcina-Goff ML. Some aspects of the airborne transmission of infection. $J$ 
R Soc Interface. 2009; 6: S767-782.

5. Eames I, Tang JW, Li Y, Wilson P. Airborne transmission of disease in hospitals. $J R$ Soc Interface. 2009; 6: S697-702.

6. Tellier R. Review of aerosol transmission of influenza A virus. Emerg Infect Dis. 2006; 12: $1657-1662$.

7. Li Y, Tang J, Noakes C, Hodgson MJ. Engineering control of respiratory infection and low-energy design of healthcare facilities. Sci Technol Built En. 2015; 21(1): 25-34.

8. Nielsen PV. Control of airborne infectious diseases in ventilated spaces. $J R$ Soc Interface. 2009; 6: S747-S755.

9. Morawska L. Droplet fate in indoor environments, or can we prevent the spread of infection. Indoor Air. 2006; 16: 335-347.

10. Wu Y, Tung TCW, Niu J. On-site measurement of tracer gas transmission between horizontal adjacent flats in residential building and cross-infection risk assessment. Build Environ. 2016; 99: 13-21.

11. Yu IT, Li Y, Wong TW, et al. Evidence of airborne transmission of the severe acute respiratory syndrome virus. N Engl J Med. 2004; 350: 1731-1739.

12. Health, Welfare \& Food Bureau, Government of the Hong Kong Special Administrative Region (HWFB-HK). SARS Bulletin (28 May 2003). Available at: http://www.info.gov.hk/info/sars/bulletin/bulletin0528e.pdf, accessed 20 March, 2017.

13. Niu JL, Tung TCW. On-site quantification of re-entry ratio of ventilation exhausts in multi-family residential buildings and implications. Indoor Air. 2008; 18: 12-26.

14. Liu XP, Niu JL, Kwok KCS, et al. Investigation of indoor air pollutant dispersion and cross-contamination around a typical high-rise residential building: wind tunnel tests. Build Environ. 2010; 45: 1769-1778.

15. Ai ZT, Mak CM, Niu JL. Numerical investigation of wind-induced airflow and interunit dispersion characteristics in multistory residential buildings. Indoor Air. 2013; 23: 417429.

16. Ai ZT, Mak CM. A study of interunit dispersion around multistory buildings with singlesided ventilation under different wind directions. Atmos Environ. 2014; 88: 1-13.

17. Ai ZT, Mak CM. Large eddy simulation of wind-induced interunit dispersion around multistory buildings. Indoor Air. 2016; 26: 259-273.

18. Mu D, Gao N, Zhu T. Wind tunnel tests of inter-flat pollutant transmission characteristics in a rectangular multi-storey residential building, Part A: Effect of wind direction. Build Environ. 2016; 108: 159-170.

19. Tang JW, Li Y, Eames I, et al. Factors involved in the aerosol transmission of infection and control of ventilation in healthcare premises. J Hosp Infect. 2006; 64: 100-114.

20. Nicas M, Nazaroff WW, Hubbard A. Toward understanding the risk of secondary airborne infection: emission of respirable pathogens. J Occup Environ Hyg. 2005; 2: 143-154.

21. Wei J, Li Y. Airborne spread of infectious agents in the indoor environment. Am J Infect Control. 2016; 44: S102-S108.

22. Chao CYH, Wan MP, Morawska L, et al. Characterization of expiration air jets and droplet size distributions immediately at the mouth opening. J Aerosol Sci. 2009; 40: 122-133.

23. Duguid JP. The size and duration of air-carriage of respiratory droplets and dropletnuclei. J Hyg. 1946; 44(6): 471-479.

24. Wells WF. Airborne contagion and air hygiene: an ecological study of droplet infection. Cambridge, MA: Harvard University Press. 1955; pp. 423.

25. Cole EC, Cook CE. Characterization of infectious aerosols in health care facilities: an aid to effective engineering controls and preventive strategies. Am J Infect Control. 1988;

This article is protected by copyright. All rights reserved. 
26: 453-464.

26. Fitzgerald D, Haas DW. Mycobacterium tuberculosis. In: Mandell GL, Bennett JE, Dolin R, editors. Principles and practice of infectious diseases. 6th edn. Philadelphia: Churchill Livingstone; 2005.

27. Papineni RS, Rosenthal FS. The size distribution of droplets in the exhaled breath of healthy human subjects. J Aerosol Med. 1997; 10(2): 105-116.

28. Edwards DA, Man JC, Brand P, et al. Inhaling to mitigate exhaled bioaerosols. PNAS. 2004; 101(50): 17383-17388.

29. Fang M, Lau APS, Chan CK, et al. Aerodynamic properties of biohazardous aerosols in hospitals. Hong Kong Med J. 2008; 14(1): 26-28.

30. Fabian P, McDevitt JJ, DeHaan WH, et al. Influenza virus in human exhaled breath: an observational study. PLoS One. 2008; 3(7): e2691.

31. Morawska L, Johnson GR, Ristovski ZD, et al. Size distribution and sites of origin of droplets expelled from the human respiratory tract during expiratory activities. J Aerosol Sci. 2009; 40(1): 256-269.

32. Almstrand AC, Bake B, Ljungstrom E, et al. Effect of airway opening on production of exhaled particles. J Appl Physiol. 2010; 108(3): 584-588.

33. Holmgren H, Ljungstrom E, Almstrand AC, et al. Size distribution of exhaled particles in the range from 0.01 to $2.0 \mu \mathrm{m}$. J Aerosol Sci. 2010; 41(5): 439-446.

34. Haslbeck K, Schwarz K, Hohlfeld JM, et al. Submicron droplet formation in the human lung. J Aerosol Sci. 2010; 41(5): 429-438.

35. Lowen AC, Mubareka S, Steel J, Palese P. Influenza virus transmission is dependent on relative humidity and temperature. PLoS Pathog. 2007; 3(10): e151.

36. Gralton J, Tovey E, Mclaws ML, Rawlinson WD. The role of particle size in aerosolized pathogen transmission: A review. J Infect. 2011; 62: 1-13.

37. World Health Organization (WHO). Infection prevention and control of epidemic- and pandemic-prone acute respiratory diseases in health care. WHO Guidelines, 2014, available at: http://apps.who.int/iris/bitstream/10665/112656/1/9789241507134_eng.pdf

38. Lindsley WG, Blachere FM, Thewlis RE, et al. Measurements of airborne influenza virus in aerosol particles from human coughs. PLoS One. 2010; 5(11): e15100.

39. Riley RL. Airborne infection. Am J Med. 1974; 57: 466-475.

40. Brachman PS. Transmission and principles of control. In: Mandell GL, Douglas RG, Bennett JE (eds), Principles and Practice of Infectious Diseases, $3^{\text {rd }}$ edn. New York: Churchill Living Stone. 1990.

41. Li Y, Leung GM, Tang JW, et al. Role of ventilation in airborne transmission of infectious agents in the built environment - a multidisciplinary systematic review. Indoor Air. 2007; 17: 2-18.

42. Xie X, Li Y, Chwang ATY, et al. How far droplets can move in indoor environments revisiting the Wells evaporation-falling curve. Indoor Air. 2007; 17: 211-225.

43. Loosli C, Lemon H, Robertson O, Appel E. Experimental airborne influenza infection: 1. Influence of humidity on survival of virus in air. Proc Soc Exp Biol Med. 1943; 53: 205206.

44. Lai MY, Cheng PK, Lim WW. Survival of severe acute respiratory syndrome coronavirus. Clin Infect Dis. 2005; 41: e67-71.

45. Thomas RJ. Particle size and pathogenicity in the respiratory tract. Virulence. 2013; 4: 847-858.

46. Koullapis PG, Kassinos SC, Bivolarova MP, Melikov AK. Particle deposition in a realistic geometry of the human conducting airways. J Biomech. 2016; 49(11): 22012212.

47. Melikov AK. Human body micro-environment: The benefits of controlling airflow

This article is protected by copyright. All rights reserved. 
interaction. Build Environ. 2015; 91: 70-77.

48. Villafruela JM, Olmedo I, San Jose JF. Influence of human breathing modes on airborne cross infection risk. Build Environ. 2016; 106: 340-351.

49. Kaushal V, Saini PS, Gupta AK. Environmental control including ventilation in hospitals. JK Science. 2004; 6(4): 229-232.

50. Beggs CB, Kerr KG, Noakes CJ, et al. The ventilation of multiple-bed hospital wards: Review and analysis. Am J Infect Control. 2008; 36(4): 250-259.

51. Qian H, Li Y. Removal of exhaled particles by ventilation and deposition in a multibed airborne infection isolation room. Indoor Air. 2010; 20: 284-297.

52. Nielsen PV, Li Y, Buus M, Winther FV. Risk of cross-infection in a hospital ward with downward ventilation. Build Environ. 2010; 45: 2008-2014.

53. Grosskopf K. Balancing ventilation and energy use in hospitals: a case study of bioaerosol transport in healthcare environments. Antimicrob Resist Infect Control. 2(Suppl. 1): 2013; 396.

54. Bolashikov ZD, Melikov AK, Kierat W, et al. Exposure of health care workers and occupants to coughed airborne pathogens in a double-bed hospital patient room with overhead mixing ventilation. HVAC\&R Res. 2012; 18(4): 602-615.

55. Pantelic J, Tham KW. Adequacy of air change rate as the sole indicator of an air distribution system's effectiveness to mitigate airborne infectious disease transmission caused by a cough release in the room with overhead mixing ventilation: a case study. HVAC\&R Res. 2013; 19: 947-961.

56. Melikov AK. Advanced air distribution: improving health and comfort while reducing energy use. Indoor Air. 2016; 26: 112-124.

57. Bolashikov ZD, Barova M, Melikov AK. Wearable personal exhaust ventilation: improved IAQ and reduced exposure to air exhaled from a sick doctor. Sci Technol Built En. 2015; 21: 1117-1125.

58. Cermak R, Melikov AK, Forejt L, Kovar O. Performance of personalized ventilation in conjunction with mixing and displacement ventilation. HVAC\&R Res. 2006; 12(2): 295311.

59. Licina D, Pantelic J, Melikov A, et al. Experimental investigation of the human convective boundary layer in a quiescent indoor environment. Build Environ. 2014; 75: 79-91.

60. Laverge J, Spilak M, Novoselac A. Experimental assessment of the inhalation zone of standing, sitting and sleeping persons. Build Environ. 2014; 82: 258-66.

61. Rim D, Novoselac A. Transport of particulate and gaseous pollutants in the vicinity of a human body. Build Environ. 2009; 44: 1840-1849.

62. Licina D, Melikov A, Pantelic J, et al. Human convection flow in spaces with and without ventilation: personal exposure to floor-released particles and cough-released droplets. Indoor Air. 2015; 25: 672-682.

63. Gupta JK, Lin C, Chen Q. Characterizing exhaled airflow from breathing and talking. Indoor Air. 2010; 20: 31-39.

64. Gupta JK, Lin CH, Chen Q. Flow dynamics and characterization of a cough. Indoor Air. 2009; 19: 517-525.

65. Melikov AK. Breathing thermal manikins for indoor environment assessment: important characteristics and requirements. Eur J Appl Physiol. 2004; 92: 710-713.

66. Melikov AK, Kaczmarczyk J. Measurement and prediction of indoor air quality using a breathing thermal manikin. Indoor Air. 2007; 17: 50-59.

67. Xu C, Nielsen PV, Liu L, et al. Human exhalation characterization with the aid of schlieren imaging technique. Build Environ. 2017; 112: 190-199. 
68. Pantelic J, Sze To GN, Tham KW, et al. Personalized ventilation as a control measure for airborne transmissible disease spread. J R Soc Interface. 2009; 6: S715-726.

69. Pantelic J, Tham KW, Licina D. Effectiveness of a personalized ventilation system in reducing personal exposure against directly released simulated cough droplets. Indoor Air. 2015; 25: 683-693.

70. VanSciver M, Miller S, Hertzberg J. Particle image velocimetry of human cough. Aerosol Sci Technol. 2011; 45: 415-422.

71. Hui DS, Chow BK, Chu LC, et al. Exhaled air and aerosolized droplet dispersion during application of a jet nebulizer. Chest. 2009; 135(3): 648-654.

72. Hui DS, Chow BK, Ng SS, et al. Exhaled air dispersion distances during noninvasive ventilation via different Respironics face masks. Chest. 2009; 136(4): 998-1005.

73. Settles GS. Visualizing full-scale ventilation airflows. ASHRAE J. 1997; 39: 19-26.

74. Settles GS. Schlieren and shadowgraph techniques. Visualising phenomena in transparent media. Berlin: Springer; 2001.

75. Craven BA, Settles GS. A computational and experimental investigation of the human thermal plume. J Fluids Eng. 2006; 128: 1251-1258.

76. Tang JW, Noakes CJ, Nielsen PV, et al. Observing and quantifying airflows in the infection control of aerosol- and airborne-transmitted diseases: an overview of approaches. J Hosp Infect. 2011; 77: 213-222.

77. Chao CYH, Wan MP. A study of the dispersion of expiratory aerosols in unidirectional downward and ceiling-return type airflows using a multiphase approach. Indoor Air. 2006; 16: 296-312.

78. Poon CKM, Lai ACK. An experimental stud quantifying pulmonary ventilation on inhalation of aerosol under steady and episodic emission. J Hazard Mater. 2011; 192: 1299-1306.

79. Nielsen PV. Fifty years of CFD for room air distribution. Build Environ. 2015; 91: 7890.

80. Yang C, Yang $\mathrm{X}$, Zhao B. Person to person droplets transmission characteristics in unidirectional ventilated protective isolation room: The impact of initial droplet size. Build Simul. 2016; 9: 597-606.

81. Li X, Niu J, Gao N. Co-occupant's exposure to exhaled pollutants with two types of personalized ventilation strategies under mixing and displacement ventilation systems. Indoor Air. 2013; 23: 162-171.

82. Zhu SW, Kato S, Yang JH. Study on transport characteristics of saliva droplets produced by coughing in a calm indoor environment. Build Environ. 2006; 41: 1691-1702.

83. Gao NP, Niu JL. Transient CFD simulation of the respiration process and inter-person exposure assessment. Build Environ. 2006; 41: 1214-1222.

84. Fluent, ANSYS FLUENT 13.0 Theory Guide, turbulence. Canonsburg, PA: ANSYS Inc. 2010.

85. Yakhot V, Orszag SA. Renormalization group analysis of turbulence: 1. Basic theory. $J$ Sci Comput. 1986; 1(1): 1-51.

86. Morawska L, Ayoko GA, Bae GN, Buonanno G, Chao CYH, Clifford S, et al. Airborne particles in indoor environment of homes, schools, offices and aged care facilities: The main routes of exposure. Environ Int. 2017; 108: 75-83.

87. Müller D, Kandzia C, Kosonen R, et al. No.19: Mixing Ventilation - Guidebook on mixing air distribution design. Rehva Guidebook, Federation of European Heating and Air-conditioning Associations. 2013.

88. Kosonen R, Melikov A, Mundt E, et al. No.23: Displacement Ventilation. Rehva Guidebook, Federation of European Heating and Air-conditioning Associations. 2017.

This article is protected by copyright. All rights reserved. 
89. Yang J, Sekhar C, Cheong DKW, Raphael B. A time-based analysis of the personalized exhaust system for airborne infection control in healthcare settings. Sci Technol Built En. 2015; 21: 172-178.

90. Li X, Niu J, Gao N. Spatial distribution of human respiratory droplet residuals and exposure risk for the co-occupant under different ventilation methods. $H V A C \& R$ Res. 2011; 17(4): 432-445.

91. Gao NP, Niu JL, Morawska L. Distribution of respiratory droplets in enclosed environment under different air distribution methods. Build Simul. 2008; 1(4): 326-335.

92. Qian H, Li Y, Nielsen PV, Hyldgaard CE, et al. Dispersion of exhaled droplet nuclei in a two-bed hospital ward with three different ventilation systems. Indoor Air. 2006; 16: 111-128.

93. Zhao B, Zhang Z, Li X. Numerical study of transport of droplets or particles generated by respiratory system indoors. Build Environ. 2005; 40: 1032-1039.

94. Habchi C, Ghali K, Ghaddar N. A simplified mathematical model for predicting cross contamination in displacement ventilation air-conditioned space. J Aerosol Sci. 2014; 76: 72-86.

95. Nielsen PV, Olmedo I, Ruiz de Adana M, et al. Airborne cross-infection risk between two people standing in surroundings with a vertical temperature gradient. HVAC\&R Res. 2012; 18(4): 552-561.

96. Yi Y, Xu W, Gupta JK, et al. Experimental study on displacement and mixing ventilation systems for a patient ward. HVAC\&R Res. 2009; 15(6): 1175-1191.

97. James M, Khan WS, Nannaparaju MR, et al. Current evidence for the use of laminar flow in reducing infection rates in total joint arthroplasty. Open Orthop J. 2015; 9: 495498.

98. Centers for Disease Control and Prevention (CDC). Guidelines for Preventing the Transmission of Mycobacterium Tuberculosis in Health-Care Settings. Atlanta, GA: U.S. Department of Health and Human Services, 2005.

99. Schlesinger A, Paul M, Gafter-Gvili A, et al. Infection-control interventions for cancer patients after chemotherapy: A systematic review and meta-analysis. Lancet Infect Dis. 2009; 9: 97-107.

100. Olmedo I, Nielsen PV, Ruiz de Adana M, Jensen RL. The risk of airborne cross-infection in a room with vertical low-velocity ventilation. Indoor Air. 2013; 23: 62-73.

101. Qian H, Li Y, Nielsen P, Hyldgaard CE. Dispersion of exhalation pollutants in a two-bed hospital ward with a downward ventilation system. Build Environ. 2008; 43: 344-354.

102.Licina D, Melikov A, Sekhar C, Tham KW. Human convective boundary layer and its interaction with room ventilation flow. Indoor Air. 2015; 25: 21-35.

103.Lipczynska A, Kaczmarczyk J, Melikov AK. Thermal environment and air quality in office with personalized ventilation combined with chilled ceiling. Build Environ. 2015; 92: 603-614.

104.Cermak R, Melikov AK. Protection of occupants from exhaled infectious agents and floor material emissions in rooms with personalized and underfloor ventilation. HVAC\&R Res. 2007; 13(1): 23-38.

105.Nielsen PV, Hyldgaard CE, Melikov A, et al. Personal exposure between people in a room ventilated by textile terminals - with and without personalized ventilation. HVAC\&R Res. 2007; 13(4): 635-643.

106. Melikov AK, Cermak R, Mayer M. Personalized ventilation: Evaluation of different air terminal devices. Energ Buildings. 2002; 34: 829-836.

107. Yang J, Sekhar SC, Cheong DKW, Raphael B. Performance evaluation of a novel personalized ventilation-personalized exhaust system for airborne infection control. Indoor Air. 2015; 25: 176-187.

This article is protected by copyright. All rights reserved. 
108. Bolashikov ZD, Melikov AK, Brand M. Reduced exposure to coughed air by a novel ventilation method for hospital patient rooms. Proceedings of ICCCS 2012 International Symposium on Contamination Control. 2012.

109. Melikov AK, Bolashikov ZD, Georgiev E. Novel ventilation strategy for reducing the risk of airborne cross infection in hospital rooms. Proceedings of Indoor Air, University of Austin, 2011.

110.Dygert RK, Dang TQ. Mitigation of cross-contamination in an aircraft cabin via localized exhaust. Build Environ. 2010; 45(9): 2015-2026.

111. Melikov AK, Dzhartov V. Advanced air distribution for minimizing airborne crossinfection in aircraft cabins. HVAC\&R Res. 2013; 19: 926-933.

112.ASHRAE Standard 62.1. Ventilation for Acceptable Indoor Air Quality. Atlanta, GA, American Society of Heating, Refrigerating and Air Conditioning Engineers. 2016.

113. Centers for Disease Control and Prevention (CDC). Guidelines for Environmental Infection Control in Health-care Facilities. Atlanta, GA: U.S. Department of Health and Human Services, 2003.

114. Bolashikov ZD, Melikov AK. Exposure to exhaled air from a sick occupant in a two-bed hospital room with mixing ventilation: effect of distance from sick occupant and air change rate. Proceeding of Indoor Air 2011, Austin, TX.

115. Bolashikov ZD, Melikov AK, Barova M. Exposure to exhaled air from a sick occupant in a two-bed hospital room with mixing ventilation: effect of posture of doctor and air change rate. Proceedings of $11^{\text {th }}$ REHVA World Congress and the $8^{\text {th }}$ Internaational Conference on Indoor Air Quality, Ventilation and Energy Conservation in Buildings. 2013.

116. Olmedo I, Nielsen PV, Ruiz de Adana M, et al. Distribution of exhaled contaminants and personal exposure in a room using three different air distribution strategies. Indoor Air. 2012; 22: 64-76.

117.Bjørn E, Nielsen PV. Dispersal of exhaled air and personal exposure in displacement ventilated rooms. Indoor Air. 2002; 12: 147-164.

118. Melikov AK, Bolashikov ZD, Kostadinov K, et al. Exposure of health care workers and occupants to coughed air in a hospital room with displacement air distribution: impact of ventilation rate and distance from coughing patient. $10^{\text {th }}$ International Conference on Healthy Buildings, Brisbane, Australia, 2012.

119.Liu L, Li Y, Nielsen PV, et al. Short-range airborne transmission of expiratory droplets between two people. Indoor Air. 2016; 27(2): 452-462.

120.Nielsen PV, Winther FV, Buus M, Thilageswaran, M. Contaminant flow in the microenvironment between people under different ventilation conditions. ASHRAE Trans. 2008; 114(2): 632-638.

121.Nielsen PV, Polak M, Jiang H, et al. Protection against cross infection in hospital beds with integrated personalized ventilation. Proceedings of Indoor Air 2008, Copenhagen, Denmark, August 17-22, 2008.

122. Bivolarova M, Kierat W, Zavrl E, et al. Control of airflow interaction in occupant vicinity for reduction of exposure to bioeffluents. Build Environ. 2017; 125: 216-226.

123.Liu S, Novoselac A. Transport of airborne particles from an unobstructed cough jet. Aerosol Sci Technol. 2014; 48(11): 1183-1194.

124.Zhang Z, Chen X, Mazumdar S, et al. Experimental and numerical investigation of airflow and contaminant transport in an airliner cabin mockup. Build Environ. 2009; 44: 85-94.

125. Noakes CJ, Fletcher LA, Sleigh PA, et al. Comparison of tracer techniques for evaluating the behavior of bioaerosols in hospital isolation rooms. Proceedings of Healthy Buildings. Syracuse, USA, 2009; Paper 504.

This article is protected by copyright. All rights reserved. 
126. Beato-Arribas B, McDonagh A, Noakes CJ, Sleigh PA. Assessing the near-patient infection risk in isolation rooms. Proceedings of Healthy Buildings. Eindhoven, The Netherlands, May 18-20, 2015; Paper 537.

127. Bivolarova M, Ondracek J, Melikov A, Zdimal V. A comparison between tracer gas and aerosol particles distribution indoors: The impact of ventilation rate, interaction of airflows, and presence of objects. Indoor Air. 2017; 27: 1201-1212.

128. Welling I, Anderson IM, Rosen G, et al. Contaminant dispersion in the vicinity of a worker in a uniform velocity field. Ann Occup Hyg. 2000; 44(3): 219-225.

129.Edge BA, Paterson EG, Settles GS. Computational study of the wake and contaminant transport of a walking human. J Fluids Eng. 2005; 127: 967-977.

130. Brohus H, Hyldig ML, Kamper S, Vachek UM. Influence of persons' movements on ventilation effectiveness. Proceedings of Indoor Air, Copenhagen, Denmark. 2008.

131. Brohus H, Balling KD, Jeppesen D. Influence of movements on contaminant transport in an operating room. Indoor Air. 2006; 16: 356-372.

132. Mazumdar S, Chen Q. Impact of moving bodies on airflow and contaminant transport inside aircraft cabins. Proceedings of the 10th International Conference on Air Distribution in Rooms, Roomvent 2007, Helsinki, Finland. 2007.

133. Mazumdar S, Yin Y, Guity A, et al. Impact of moving objects on contaminant concentration distributions in an inpatient room with displacement ventilation. $H V A C \& R$ Res. 2010; 16(5): 545-564.

134. Halvonova B, Melikov AK. Performance of "ductless" personalized ventilation in conjunction with displacement ventilation: Impact of disturbances due to walking person(s). Build Environ. 2010; 45: 427-436.

135.Han Z, Sze To GN, Fu SC, Chao CYH, Weng W, Huang Q. Effect of human movement on airborne disease transmission in an airplane cabin: study using numerical modeling and quantitative risk analysis, BMC Infect Dis. 2014; 14, 434.

136.Leung WT, Sze-To GN, Chao CYH, Yu SC, Kwan JK. Study on the inter-zonal migration of airborne infectious particles in an isolation ward using benign bacteria. Indoor Air. 2013; 23: 148-161.

137.Villafruela JM, San José JF, Castro F, Zarzuelo A. Airflow patterns through a sliding door during opening and foot traffic in operating rooms. Build Environ. 2016; 109: 190198.

138.Licina D, Melikov A, Sekhar C, Tham KW. Transport of gaseous pollutants by convective boundary layer around a human body. Sci Technol Built Environ. 2015; 21(8): 1175-1186.

139. Bolashikov Z, Melikov A, Velte C, et al. Airflow characteristics at the breathing zone of a seated person: interaction of the free convection flow and an assisting locally supplied flow from below for personalized ventilation application. Proceedings of Roomvent. 2011.

140.Nielsen PV, Zajas JJ, Litewnicki M, Jensen RL. Breathing and cross-Infection risk in the microenvironment around people. ASHRAE Trans. 2014; 120: 1-8.

141.ISO Standard 9920. ISO International Standard ISO FDIS 9920, Ergonomics of the thermal environment - estimation of the thermal insulation and water vapour resistance of a clothing ensemble. Geneva, Switzerland: International Standard Organization for Standardization, 2007.

142.ASHRAE Handbook. Thermal Comfort. ASHRAE Handbook of Fundamentals 9.1-9.6. Atlanta, GA, American Society of Heating, Refrigerating and Air Conditioning Engineers. 2013.

143.Xu C, Nielsen PV, Gong G, et al. Influence of air stability and metabolic rate on exhaled flow. Indoor Air. 2015; 25: 198-209.

This article is protected by copyright. All rights reserved. 
144. Brohus H, Nielsen PV. Personal exposure in displacement ventilated rooms. Indoor Air. 1996; 6: 157-167.

145. Grymer LF, Helberg O, Pedersen OF, Rasmussen TR. Acoustic rhinometry: values from adults with subjective normal nasal patency. Rhinology. 1991; 29: 35-47.

146. Haselton FR, Sperandio PGN. Convective exchange between the nose and the atmosphere. J Appl Physiol. 1988; 64(6): 2575-2581.

147.Hyldgaard CE. Humans as a source of heat and air pollution. Proceedings of ROOMVENT '94, $4^{\text {th }}$ International Conference on Air Distribution in Rooms, Krakow, Poland, 1994; 1: 413-433.

148. Cao G, Nielsen PV, Jensen RL, et al. Protected zone ventilation and reduced personal exposure to airborne cross-infection. Indoor Air. 2015; 25: 307-319.

149. Gao NP, Niu JL. Modeling particle dispersion and deposition in indoor environments. Atmos Environ. 2007; 41: 3862-3876.

150. Yin Y, Gupta JK, Zhang X, et al. Distributions of respiratory contaminants from a patient with different postures and exhaling modes in a single-bed inpatient room. Build Environ. 2011; 46: 75-81.

151. Yan W, Zhang Y, Sun Y, Li D, Experimental and CFD study of unsteady airborne pollutant transport within an aircraft cabin mock-up. Build Environ. 2009; 44: 34-43.

152. Altman PL, Dittmer DS. Respiration and Circulation, Bethesda, Maryland, Federation of American Societies for Experimental Biology, 1971.

153. Araujo GAL, Freire RCS, Silva JF, et al. Breathing Flow Measurement with Constant Temperature Hot-Wire Anemometer for Forced Oscillation Technique. Proceedings of the $21^{\text {st }}$ IEEE, Como, Italy, Instrumentation and Measurement Technology Conference. 2004; 1: 730-733.

154. Hoppe P. Temperatures of expired air under varying climatic conditions. Int J Biometeor. 1981; 25(2): 127-132.

155. Tang JW, Nicolle AD, Klettner CA, et al. Airflow dynamics of human jets: sneezing and breathing - potential sources of infectious aerosols. PloS One. 2013; 8(4): e59970.

156.Xie X, Li Y, Sun H, Liu L. Exhaled droplets due to talking and coughing. $J R$ Soc Interface. 2009; 6: S703-714.

157.Kwon SB, Park J, Jang J, et al. Study on the initial velocity distribution of exhaled air from coughing and speaking. Chemosphere. 2012; 87(11): 1260-1264.

158.Zhu SW, Kato S, Murakami S, Hayashi T. Study on inhalation region by means of CFD analysis and experiment. Build Environ. 2005; 40: 1329-1336.

159. Mahajan RP, Singh P, Murty GE, Aitkenhead AR. Relationship between expired lung volume, peak flow rate and peak velocity time during a cough manoeuvre. Br J Anaesth. 1994; 72: 298-301.

160.Tang JW, Nicolle A, Pantelic J, et al. Airflow dynamics of coughing in healthy human volunteers by shadowgraph imaging: an aid to aerosol infection control. PLoS One. 2012; 7: e34818.

161. Cao G, Liu S, Boor BE, Novoselac A. Characterizing the dynamic interactions and exposure implications of a particle-laden cough jet with different room airflow regimes produced by low and high momentum jets. Aerosol Air Qual Res. 2015; 15: 1955-1966.

162. Sherman MH. Tracer-gas techniques for measuring ventilation in a single zone. Build Environ. 1990; 25(4): 365-374.

163.Laussmann D, Helm D. Air change measurements using tracer gases: methods and results. Significance of Air change for Indoor Air Quality. InTechOpen, Rijeka, Croatia, 2011.

164.Zhang H, Li D, Xie L, Xiao Y. Documentary research of human respiratory droplet characteristics. Procedia Eng. 2015; 121: 1365-1374.

This article is protected by copyright. All rights reserved. 
165. Morawska L, Afshari A, Bae GN, et al. Indoor aerosols: from personal exposure to risk assessment. Indoor Air. 2013; 23: 462-487.

166.Lindsley WG, Pearce TA, Hudnall JB, et al. Quantity and size distribution of coughgenerated aerosol droplets produced by influenza patients during and after illness. $J$ Occup Environ Hyg. 2012; 9(7): 443-449.

167. Yang S, Lee GWM, Chen CM, et al. The size and concentration of droplets generated by coughing in human subjects. J Aerosol Med. 2007; 20(4): 484-494.

168.Zayas G, Chiang MC, Wong E, et al. Cough aerosol in healthy participants: fundamental knowledge to optimize droplet-spread infectious respiratory disease management. $B M C$ Pulm Med. 2012; 12:11.

169.Johnson GR, Morawska L. The mechanism of breath aerosol formation. J Aerosol Med Pulm Drug Deliv. 2009; 22: 229-237.

170.Holmér I. Thermal manikin history and applications. Eur J Appl Physiol. 2004; 92: 614618.

171.McCullough EA. The use of thermal manikins to evaluate clothing and environmental factors. Proceedings of the $10^{\text {th }}$ conference on environmental ergonomics, Fukuoka, Japan, September, 2002, pp. 427-430.

172. Topp C, Hesselholt P, Trier MR, Nielsen PV. Influence of geometry of thermal manikins on room airflow. Proceedings of Healthy Buildings 2003, National University of Singapore, Singapore. 2003.

173.Zukowska D, Melikov A. Popiolek Z. Impact of geometry of a sedentary occupant simulator on the generated thermal plume: Experimental investigation. HVAC\&R Res. 2012; 18 (4): 795-811.

174.Zukowska D, Melikov A, Popiolek Z. Impact of personal factors and furniture arrangement on the thermal plume above a sitting occupant. Build Environ. 2012; 49: $104-116$.

175.Zukowska D, Melikov A, Popiolek Z. Impact of thermal plumes generated by occupant simulators with different complexity of body geometry on airflow pattern in rooms. In: Proceedings of the 7th International Thermal Manikin and Modeling Meeting - 7I3M, Coimbra, Portugal, 2008; Paper 8.

176.Licina D, Melikov A, Sekhar C, Tham KW, Air temperature investigation in microenvironment around a human body. Build Environ. 2015; 92: 39-47.

177.Feng L, Yao S, Sun H, et al. TR-PIV measurement of exhaled flow using a breathing thermal manikin. Build Environ. 2015; 94: 683-693.

178.Sze To GN, Wan MP, Chao CYH, et al. Experimental study of dispersion and deposition of expiratory aerosols in aircraft cabins and impact on infectious disease transmission. Aerosol Sci Technol. 2009; 43: 466-485.

179. Marr D, Khan M, Glauser M, et al. On particle image velocimetry (PIV) measurements in the breathing zone of a thermal breathing manikin, ASHRAE Trans. 2005; 111(2): 299-305.

180. Marr D, Spitzer I, Glauser M, Anisotropy in the breathing zone of a thermal manikin, Exp Fluids. 2008; 44: 661-673.

181. Tang JW, Liebner TJ, Craven BA, Settles GS. A Schlieren optical study of the human cough with and without wearing masks for aerosol infection control. $J R$ Soc Interface. 2009; 6(Suppl. 6): S727-736.

182. Tang JW, Settles GS. Coughing and masks. N Engl J Med. 2009; 361: e62.

183.Licina D, Tham KW, Melikov AK, Sekhar C. Airflow characteristics and pollution distribution around a thermal manikin - Impact of specific personal and indoor environmental factors. ASHRAE Trans. 2016; 122: 366-379.

184.Hinze JO. Turbulence. New York: McGraw-Hill Publishing Co. 1975.

This article is protected by copyright. All rights reserved. 
185. Melikov A, Brand M, Fang L. Reduced exposure to coughed air by advanced air distribution, Proceedings of the 11th International Conference on Air Distribution in Rooms - Roomvent 2009, Busan, Korea, May 24-27, 2009; paper S0297.

186. Nazaroff WW. Indoor particle dynamics. Indoor Air. 2004; 14: 175-183.

187. Bennett DH, McKone TE, Evans JS, et al. Defining intake fraction. Environ Sci Technol. 2002; 36(9): 206A-211A.

188. Nazaroff WW. Inhalation intake fraction of pollutants from episodic indoor emissions. Build Environ. 2008; 43: 267-277.

189. Riley EC, Murphy G, Riley RL. Airborne spread of measles in a suburban elementary school. Am J Epidemiol. 1978; 107: 421-432.

190. Rudnick SN, Milton DK. Risk of indoor airborne infection transmission estimated from carbon dioxide concentration. Indoor Air. 2003; 13(3): 237-245.

191.Noakes CJ, Sleigh PA. Applying the Wells-Riley equation to the risk of airborne infection in hospital environments: The importance of stochastic and proximity effects. Proceedings of Indoor Air 2008. Copenhagen, Denmark, August 17-22, 2008.

192.Sze To GN, Wan MP, Chao CYH, et al. A methodology for estimating airborne virus exposures in indoor environments using the spatial distribution of expiratory aerosols and virus viability characteristics. Indoor Air. 2008; 18: 425-438.

193. Haas CN, Rose JB, Gerba CP. Quantitative microbial risk assessment. New York, NY, John Wiley \& Sons, Inc., 1999.

194.Lin Z, Yao T, Chow TT, Fong KF, Chan LS. Performance evaluation and design guidelines for stratum ventilation. Build Environ. 2011; 46: 2267-2279.

195. Sørensen DN, Nielsen PV. Quality control of computational fluid dynamics in indoor environments. Indoor Air. 2003; 13: 2-17.

196.Zhang Z, Zhang W, Zhai Z, Chen Q. Evaluation of various turbulence models in predicting airflow and turbulence in enclosed environments by CFD: part 2: comparison with experimental data from literature. HVAC\&R Res. 2007; 13(6): 871-886.

197.Davidson L, Nielsen PV, Sveningsson A. Modificaation of the V2-f model for the flow in a 3D wall jet. Turbul Heat Mass Transf. 2003; 4: 577-584.

198. Smagorinsky J. General circulation experiments with the primitive equations: the basic experiment. Mon Weather Rev. 1963; 91: 99-164.

199.Launder BE, Spalding DB. The numerical computation of turbulent flows. Comput Methods Appl Mech Eng. 1974; 3: 269-289.

200.Li Y, Nielsen PV. CFD and ventilation research. Indoor Air. 2011; 21: 442-453.

201.Nielsen PV. Computational fluid dynamics and room air movement. Indoor Air. 2004; 14: 134-143.

202.Chen Q. Ventilation performance prediction for buildings: a method overview and recent applications. Build Environ. 2009; 44: 848-858.

203.Awbi HB. Ventilation of Buildings, 2nd edn, London, Spon Press, 2003.

204.Wilcox DC. Turbulence Modeling for CFD. La Canada, CA, USA, DCW Industries, 2006.

This article is protected by copyright. All rights reserved. 